\title{
A New Real-Time Quantum Efficiency Measurement System
}

\author{
David L. Young 1 , Brian Egaas ${ }^{2}$, \\ Scott Pinegar ${ }^{1}$, and Paul Stradins ${ }^{1}$
}

${ }^{1}$ National Renewable Energy Laboratory, Golden, Colorado 80401 (USA)

${ }^{2}$ Colorado School of Mines, Golden, Colorado 80401 (USA)

NREL/PR-520-43323

Presented at the 33rd IEEE Photovoltaic Specialist Conference held May 11-16, 2008 in San Diego, California 


\section{Information-Rich Quantum Efficiency Graphs}
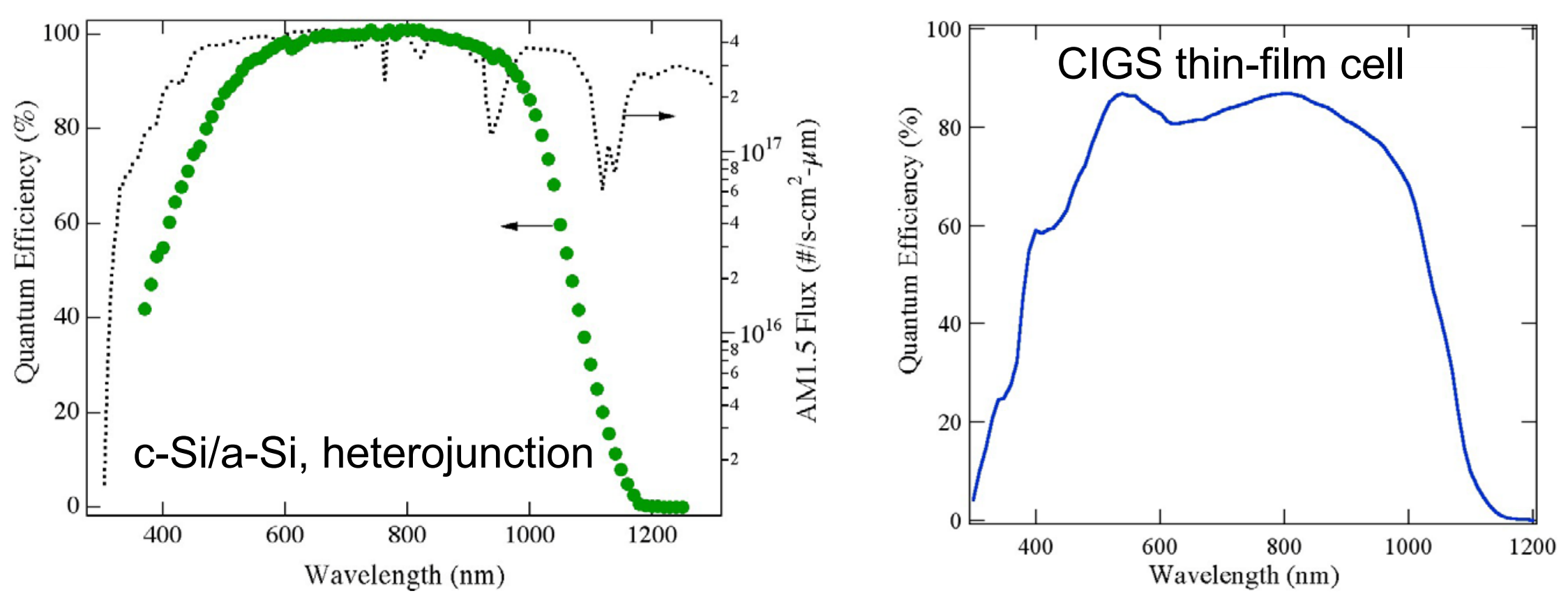

- Spectral response (current loss)

- Spatial response

"Blue" - front, "Red" - back

surfaces, bulk

thin-film layers (thickness, composition, Bandgap)

- Diffusion length (modeling) (Kieliba, JAP 2006)

- Recombination centers (QE(T)) (Wagner,APL 2003)

- Junction physics, impurity diffusion (QE(V)) (Batzner TSF 2003),(a-Si:H cells) 


\section{Information-Rich Quantum Efficiency Graphs}
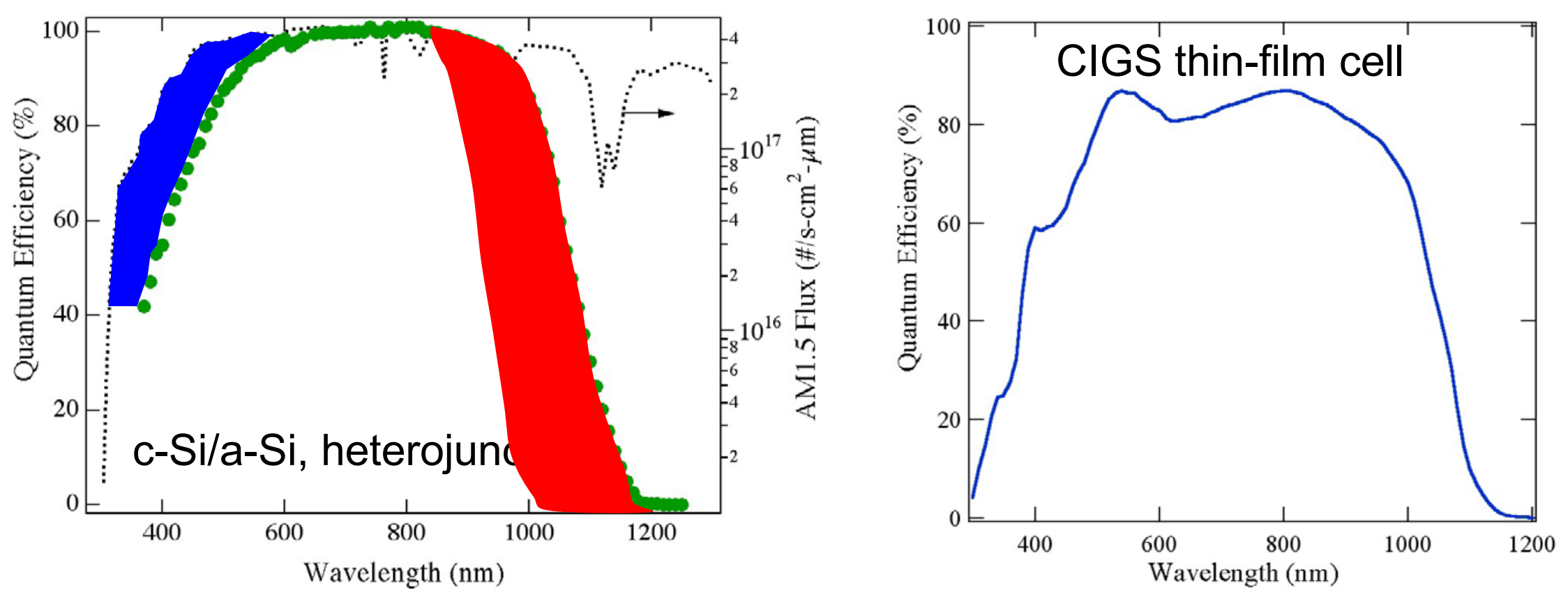

- Spectral response (current loss)

- Spatial response

"Blue" - front, "Red" - back

surfaces, bulk

thin-film layers (thickness, composition, Bandgap)

- Diffusion length (modeling) (Kieliba, JAP 2006)

- Recombination centers (QE(T)) (Wagner,APL 2003)

- Junction physics, impurity diffusion (QE(V)) (Batzner TSF 2003),(a-Si:H cells) 


\section{Information-Rich Quantum Efficiency Graphs}

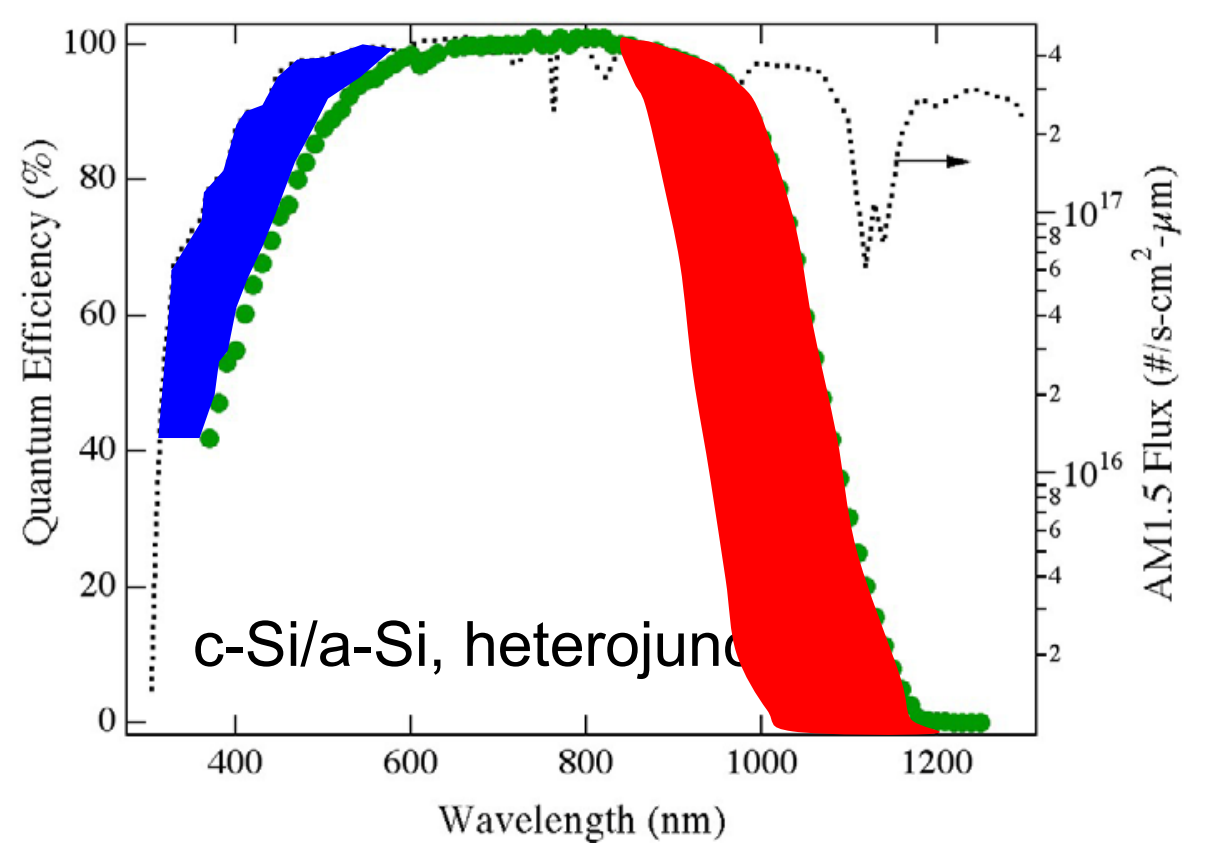

- Spectral response (current loss)

- Spatial response

"Blue" - front, "Red" - back

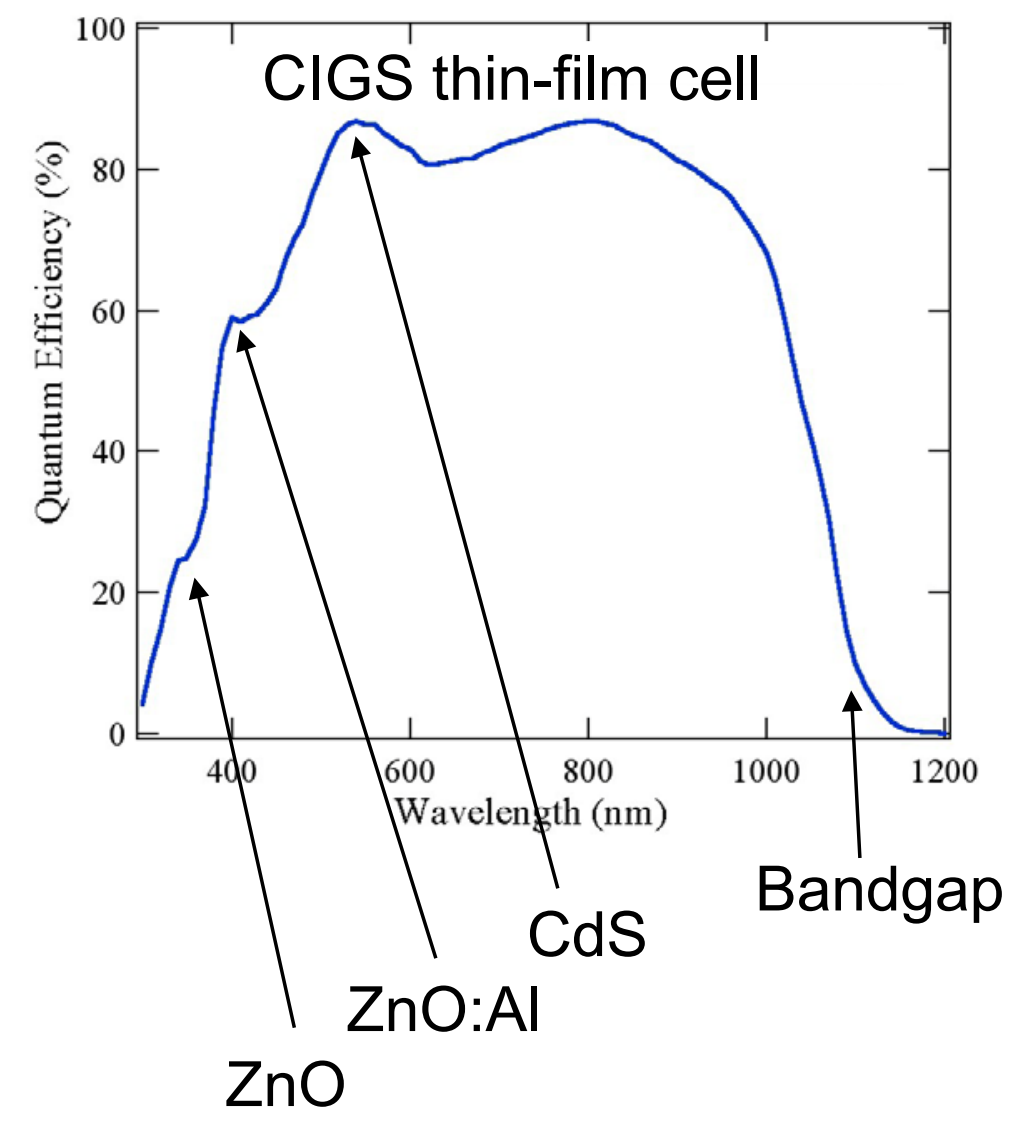

surfaces, bulk

thin-film layers (thickness, composition, Bandgap)

- Diffusion length (modeling) (Kieliba, JAP 2006)

- Recombination centers (QE(T)) (Wagner,APL 2003)

- Junction physics, impurity diffusion (QE(V)) (Batzner TSF 2003),(a-Si:H cells) 


\section{So, why don't we use QE graphs more in research and industry?}

Traditional QE method

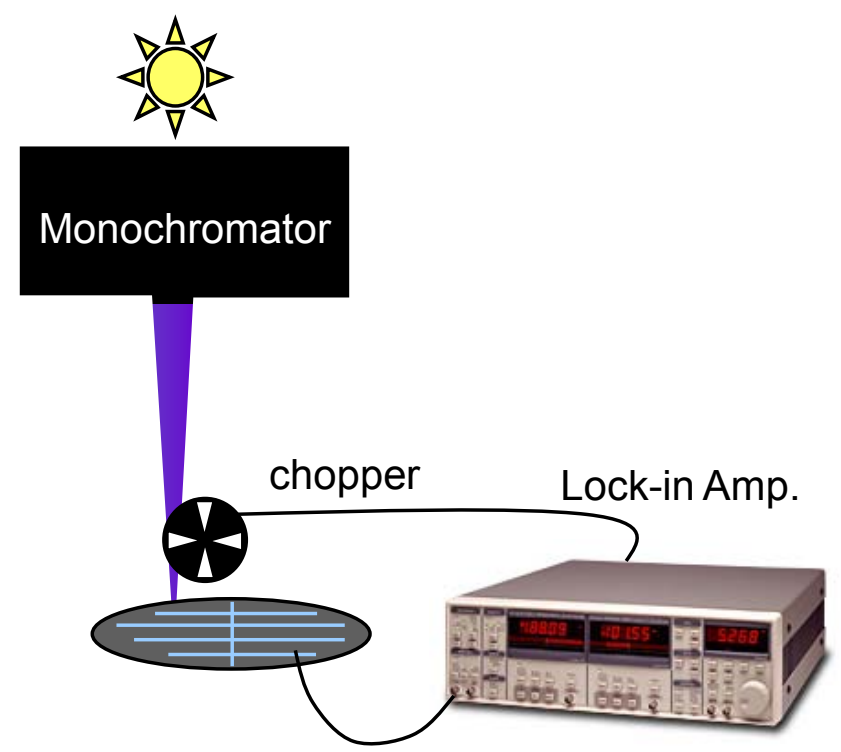

Serial measurement $\sim 5-20$ mins

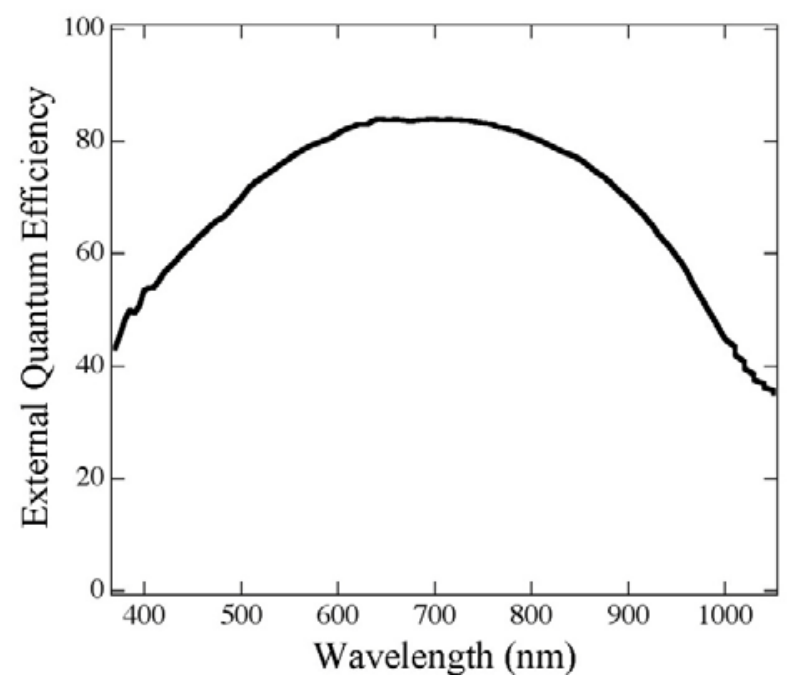

Time! (money, lack of graduate students)

New method

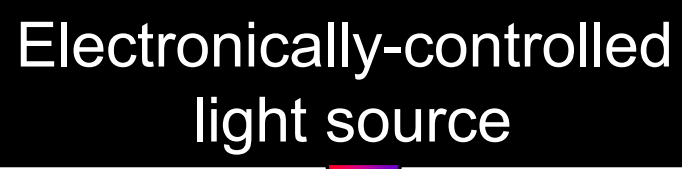

Parallel measurement $\sim 0.1 \mathrm{sec}$

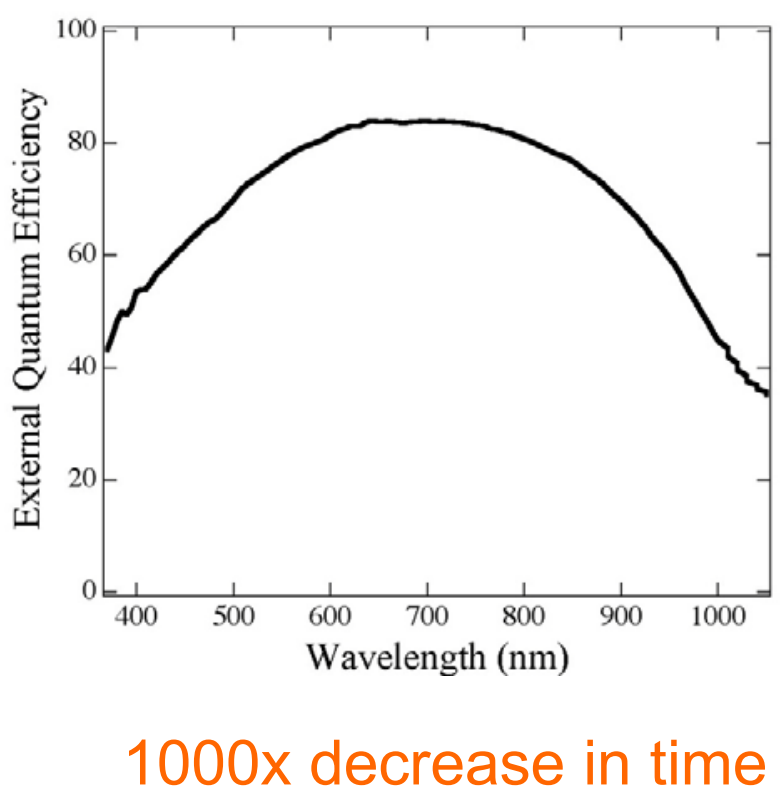


New method: Real -Time Quantum Efficiency measurement system (RTQE) Electronically-Controlled LED light source

\begin{tabular}{|l|l|l|}
\hline $\begin{array}{l}\text { LED } \\
(\#, \text { color })\end{array}$ & $\begin{array}{l}\lambda_{\text {peak }} \\
(\mathrm{nm})\end{array}$ & $\begin{array}{l}\text { Drive- } \\
\text { frequency } \\
(\mathrm{Hz})\end{array}$ \\
\hline 1, Red & 700 & 1000 \\
\hline 2, Yellow & 600 & 1153 \\
\hline 3, Green & 550 & 1262 \\
\hline 4, Blue & 470 & 875 \\
\hline$\ldots$ & - & - \\
\hline
\end{tabular}

$\begin{array}{lllll}f_{1} & f_{2} & f_{3} & f_{4} & \begin{array}{l}\text { Sine wave generators } \\ \text { (frequency, amplitude) }\end{array}\end{array}$

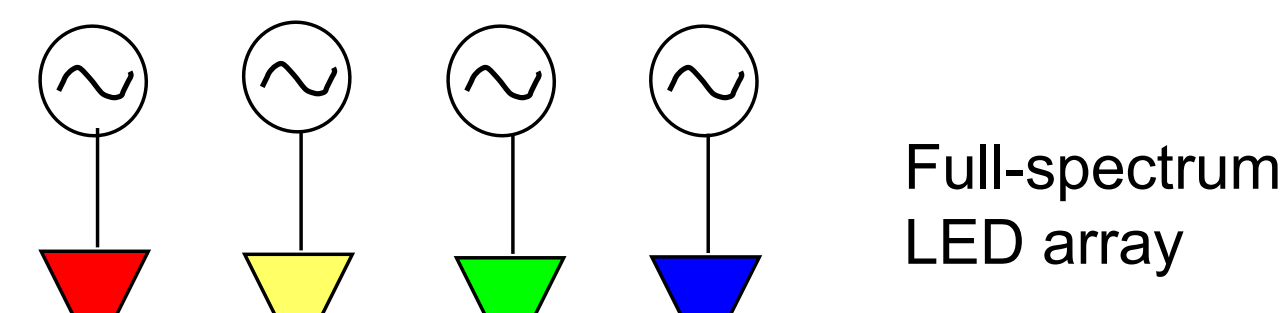

Parallel processing of information from an array of spectral channels encoded in modulated frequency bands 
New method: Real -Time Quantum Efficiency measurement system (RTQE)

\section{Electronically-Controlled LED light source}

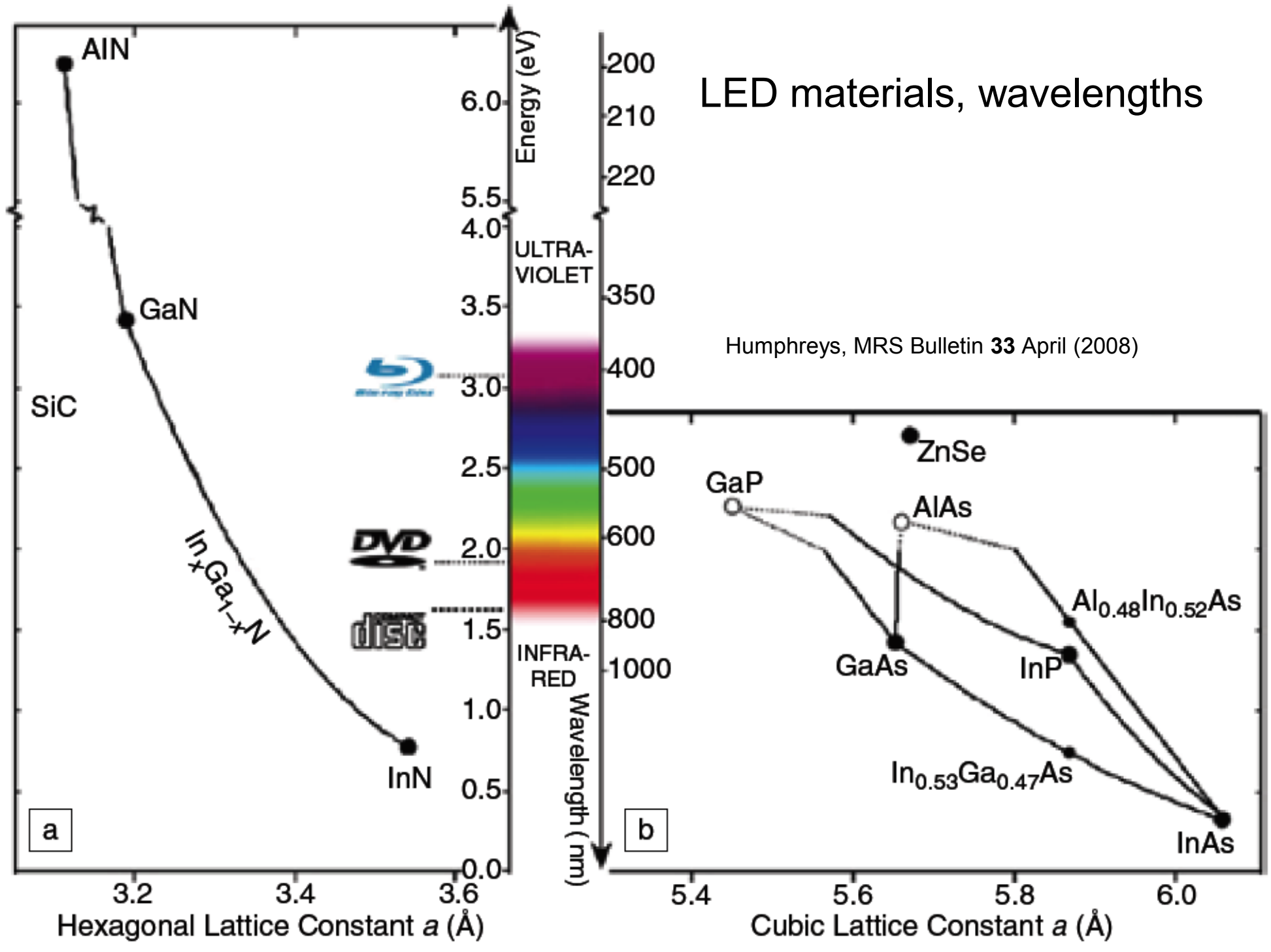


New method: Real -Time Quantum Efficiency measurement system (RTQE) Electronically-Controlled LED light source

\section{8-color LED array (2004)}

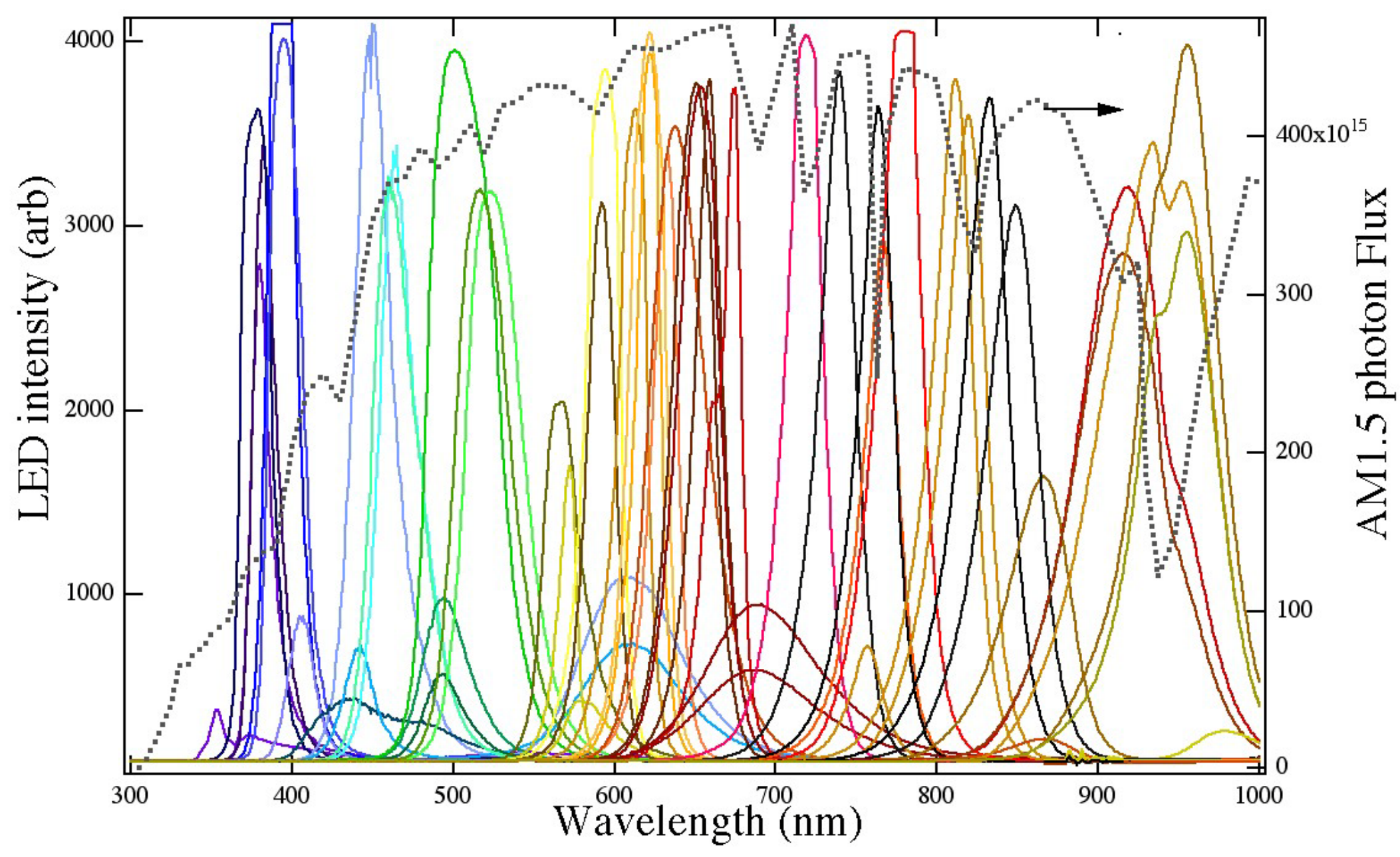


Principle of operation $f$, Sine wave drive frequency $\lambda$, LED emission wavelength analog-to-digital

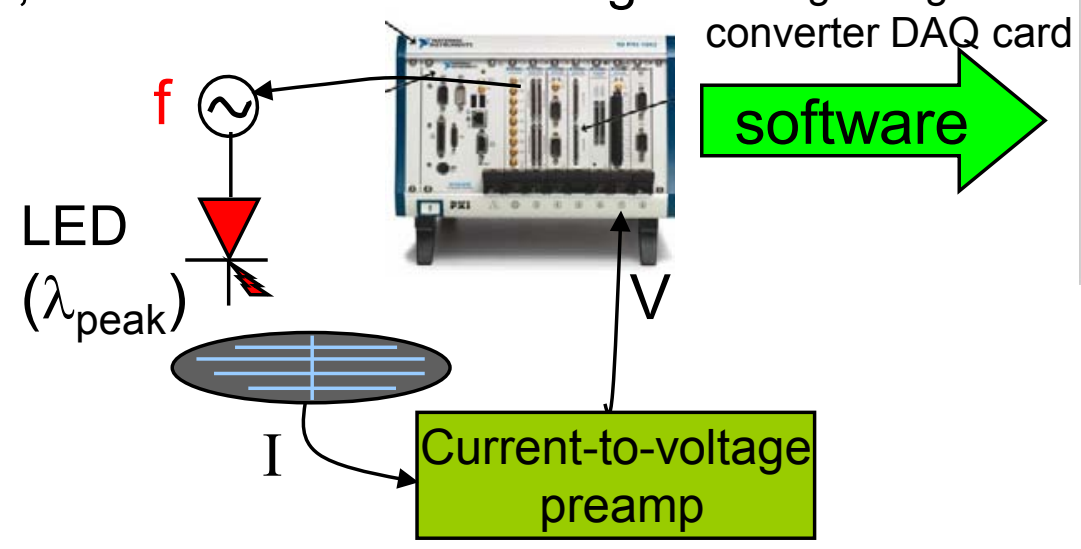

voltage vs time

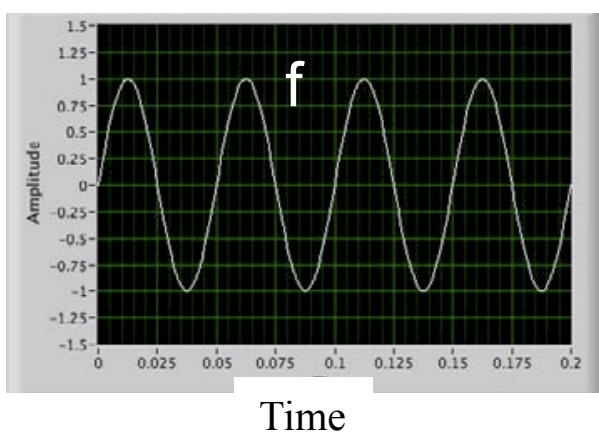

Time

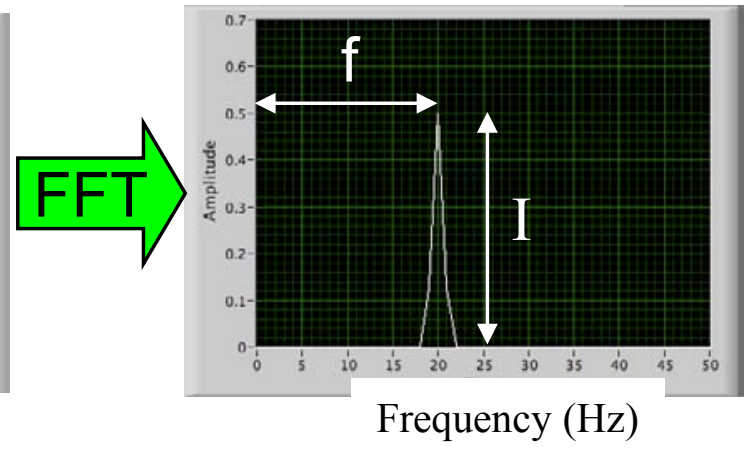

$$
\mathrm{f}_{\lambda}, \mathrm{QE}=\mathrm{K}\left(\mathrm{I}\left(\mathrm{f}_{\lambda}\right)\right)
$$
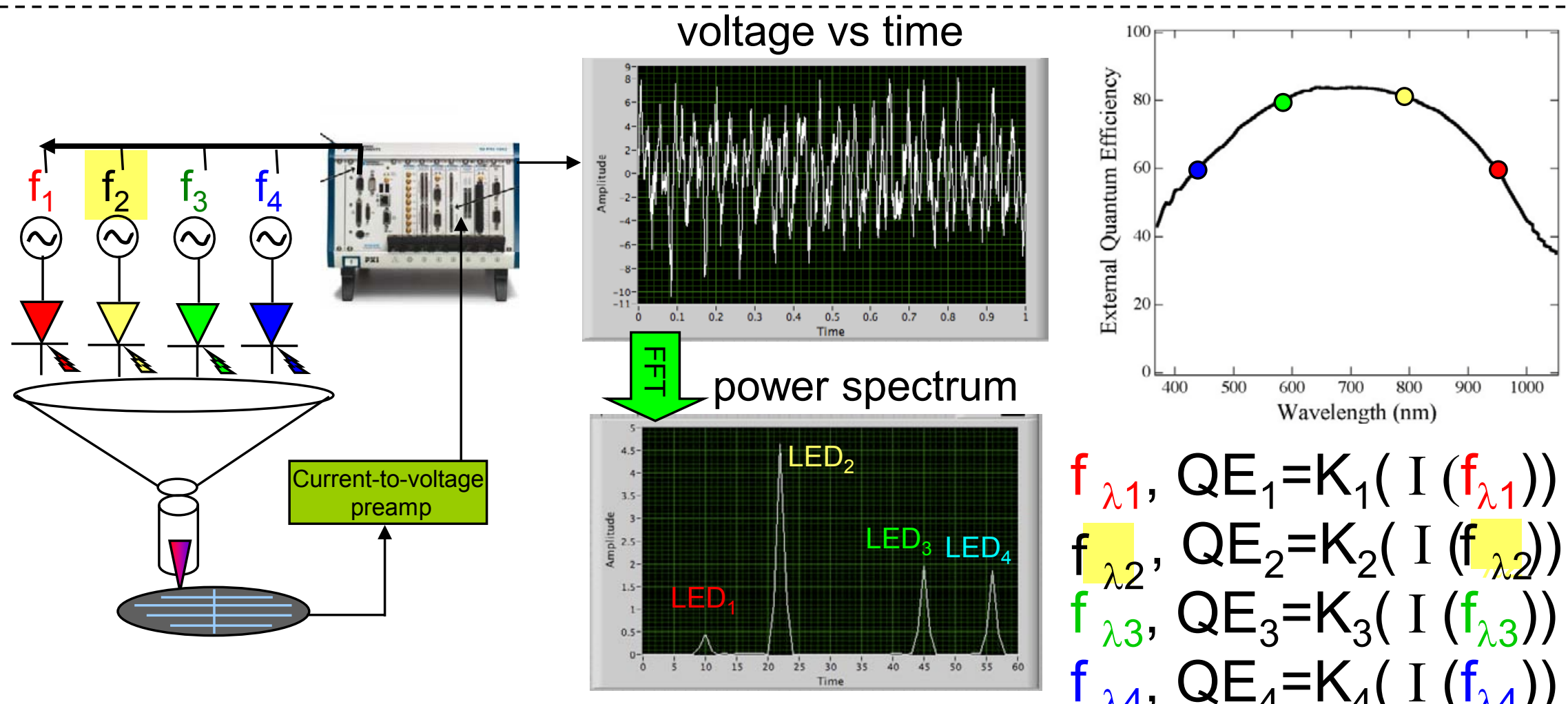

$\mathrm{f}_{\lambda 1}, \mathrm{QE}_{1}=\mathrm{K}_{1}\left(\mathrm{I}\left(\mathrm{f}_{\lambda 1}\right)\right)$

$f_{\lambda 2}, Q_{2}=K_{2}\left(I\left(f_{\lambda 2}\right)\right)$

$\mathrm{f}_{\lambda 3}, \mathrm{QE}_{3}=\mathrm{K}_{3}\left(\mathrm{I}\left(\mathrm{f}_{\lambda_{3}}\right)\right)$

$\mathrm{f}_{\lambda 4}, \mathrm{QE}_{4}=\mathrm{K}_{4}\left(\mathrm{I}\left(\mathrm{f}_{\lambda_{4}}\right)\right)$ 
Proof of concept: 10-LED Real-Time QE system prototype

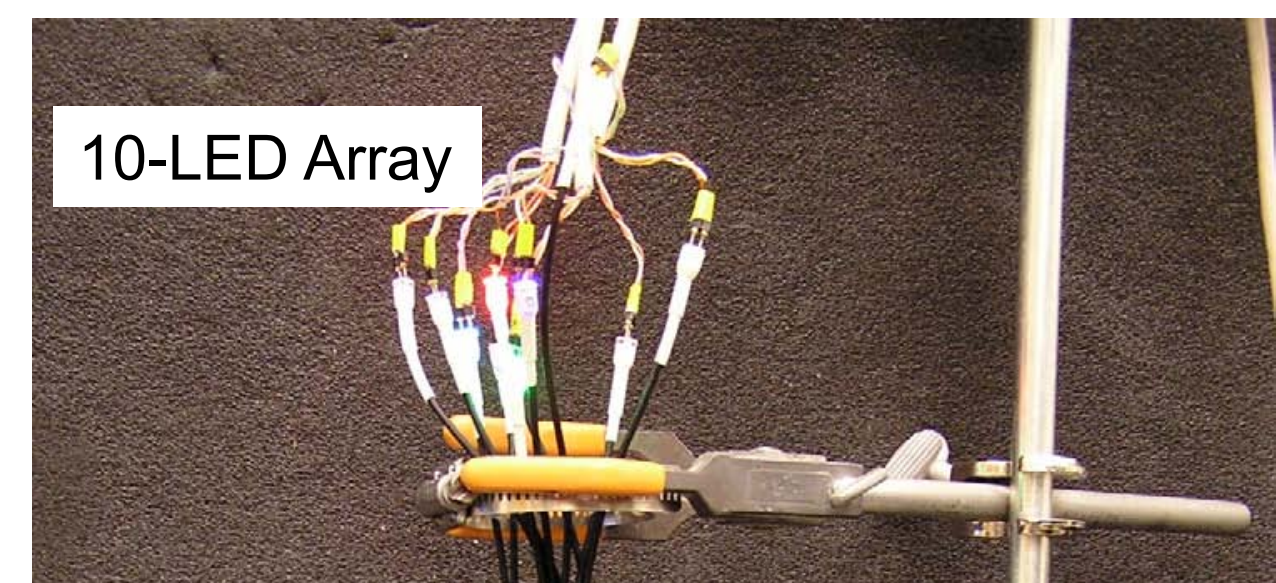

10 LEDs were chosen to span the Spectral response range of $\mathrm{C}-\mathrm{Si}$.

Optical Fibers

Focusing optics

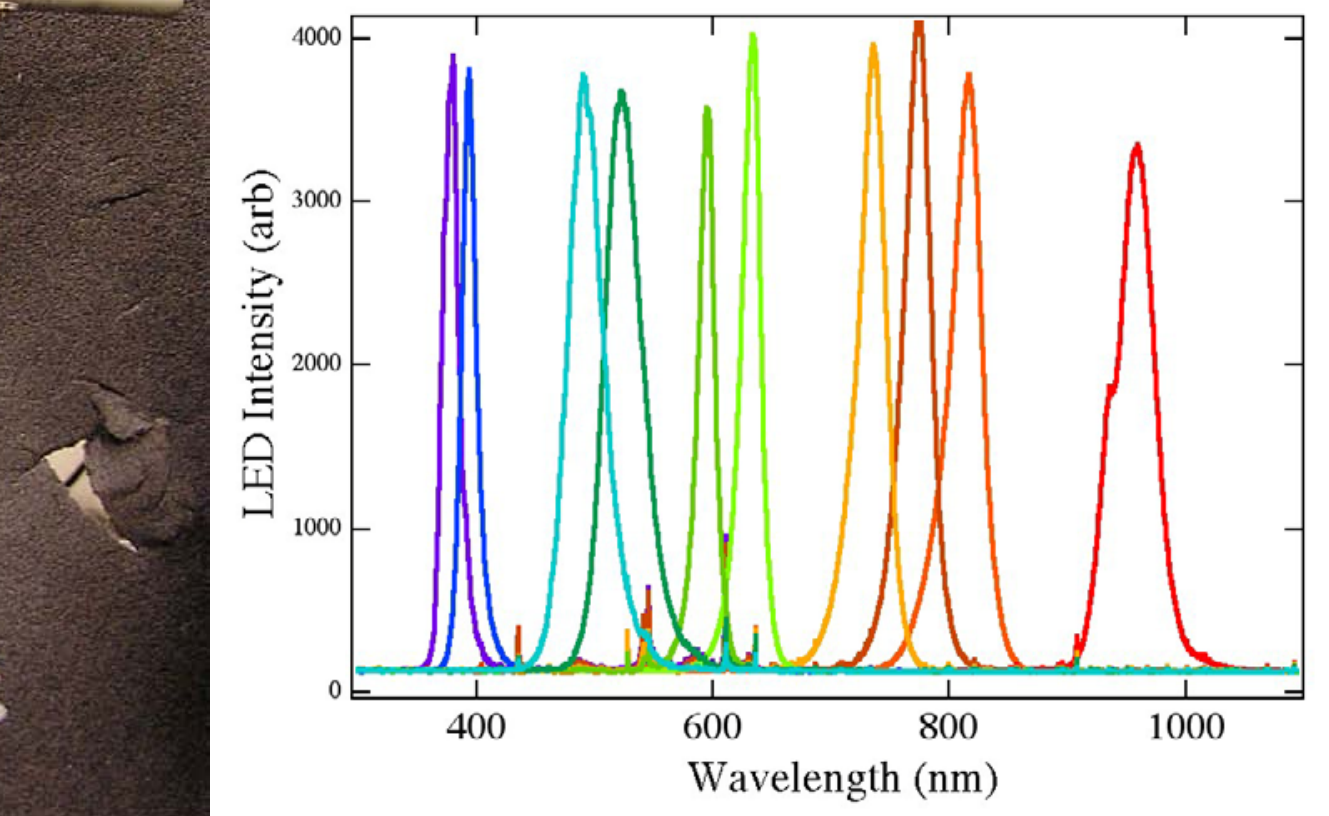


10-LED array prototype

$\begin{array}{llllllllllllll}\mathrm{f}_{1} & \mathrm{f}_{2} & \mathrm{f}_{3} & \mathrm{f}_{4} & \mathrm{f}_{5} & \mathrm{f}_{6} & \mathrm{f}_{7} & \mathrm{f}_{8} & \mathrm{f}_{9} & \mathrm{f}_{10}\end{array}$

(2)(2)(2)(2)(2) 山山山山山山山山山
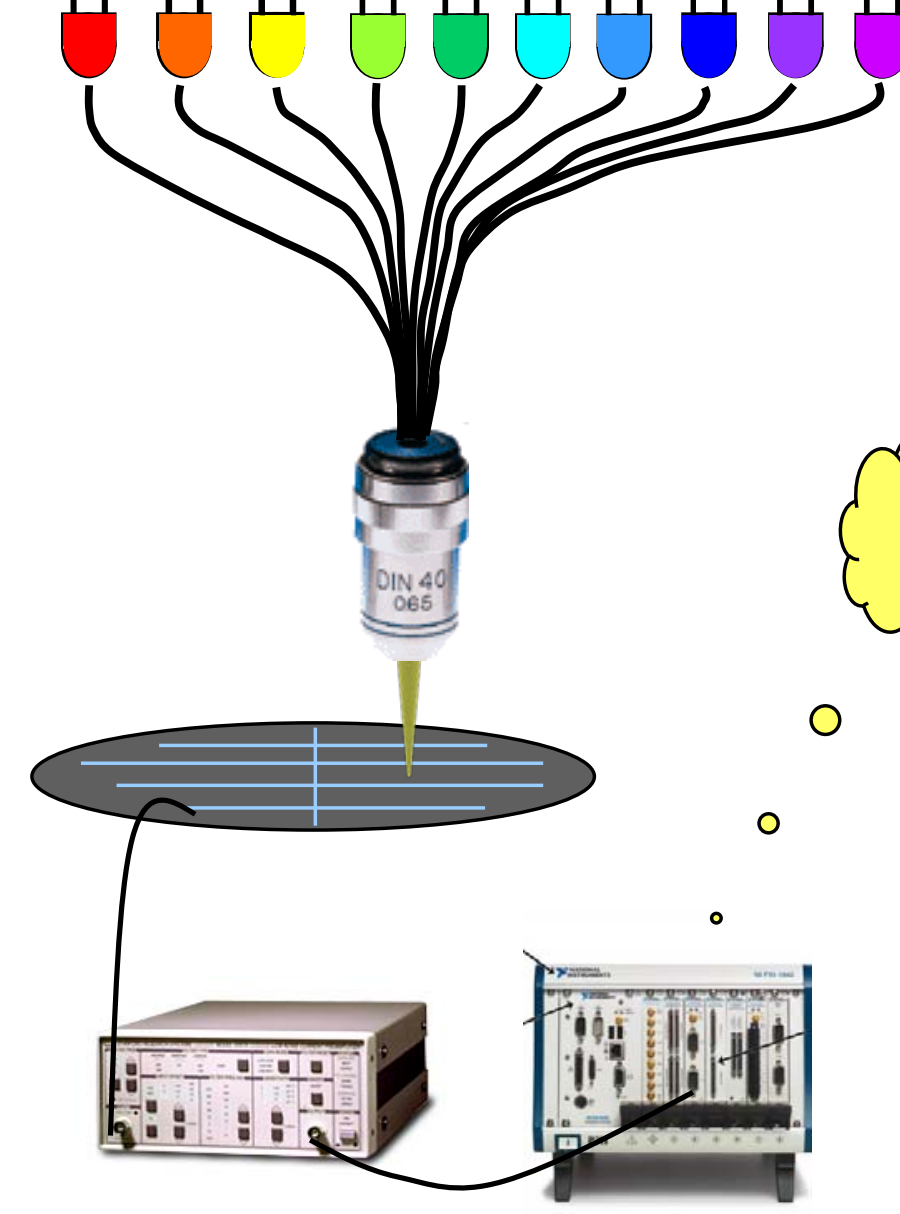

Raw Data

Dev1/aio
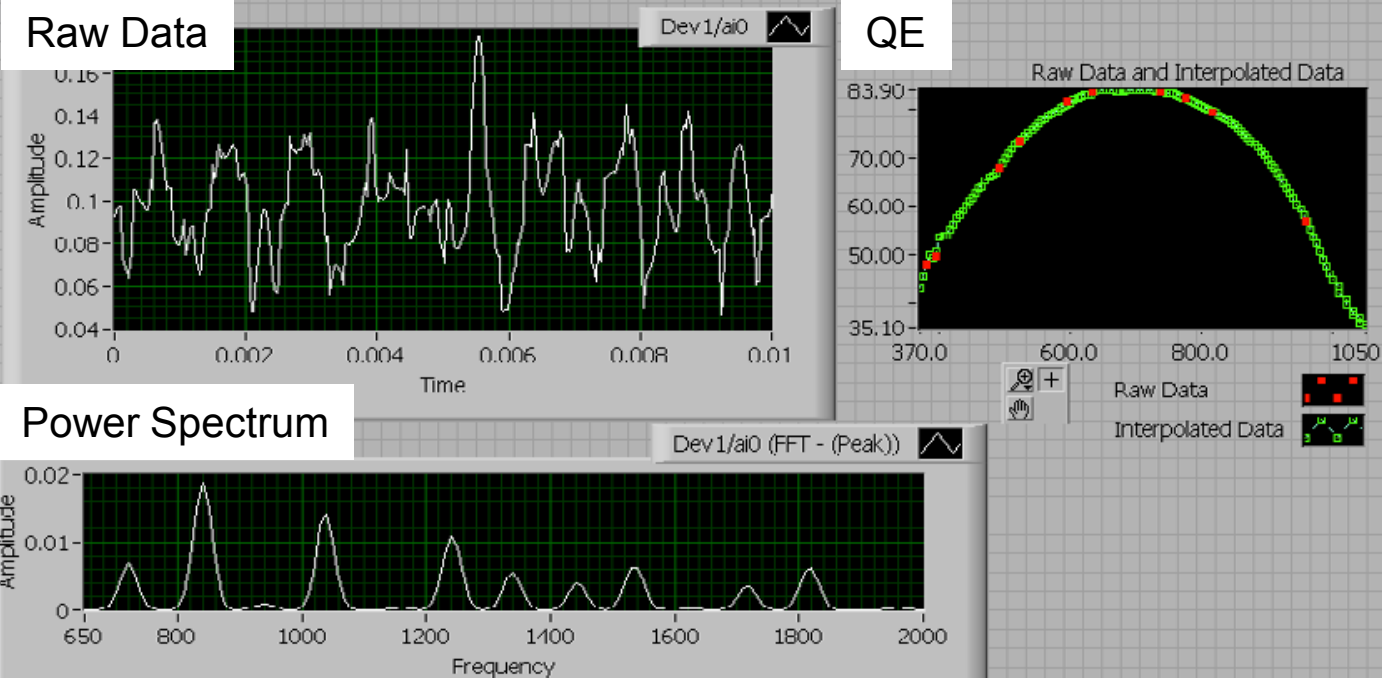

ii (FFT - (Peak)) 入 reak 6 Dev1/aii (FFT - (Peak)) 入 reak 48 Dev1/aio (FFT - (Peak)) 入
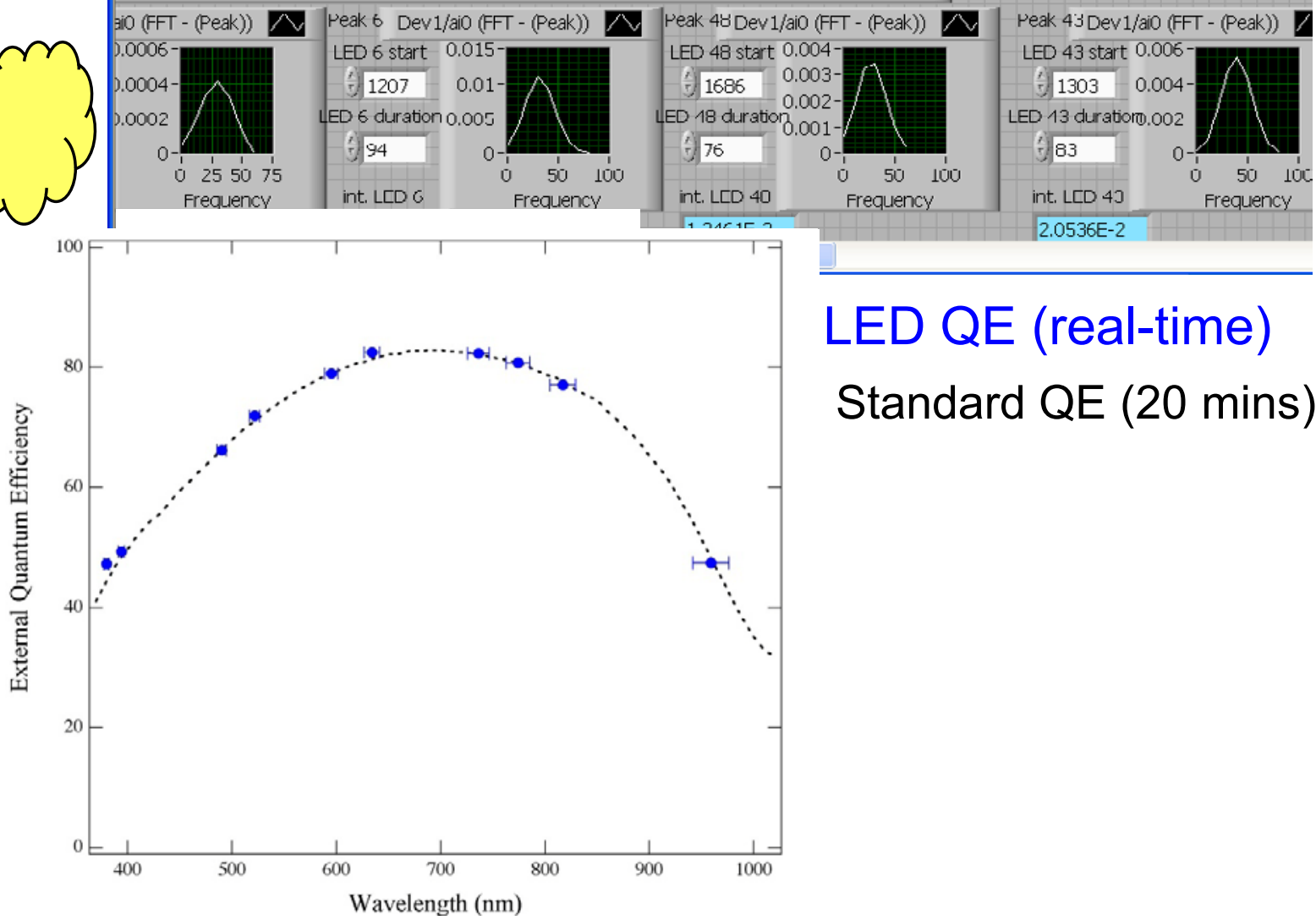

LED QE (real-time)

Standard QE (20 mins) 


\section{The Real-Time QE system is:}

- fast

Parallel processing of information from an array of spectral channels encoded in modulated frequency bands

- inexpensive

- all solid-state

- robust

- Replace traditional lab-based QE systems

\section{Expanded Applications}

- In-line diagnostics

- Spatial QE mapping

- Multi-junction QE measurements 


\section{In-line QE for solar cell manufacturing}

Benefits:

- In-line diagnostics for process control

- Device physics feedback

- Spectral-matching cell binning to maximize module KW-hr output

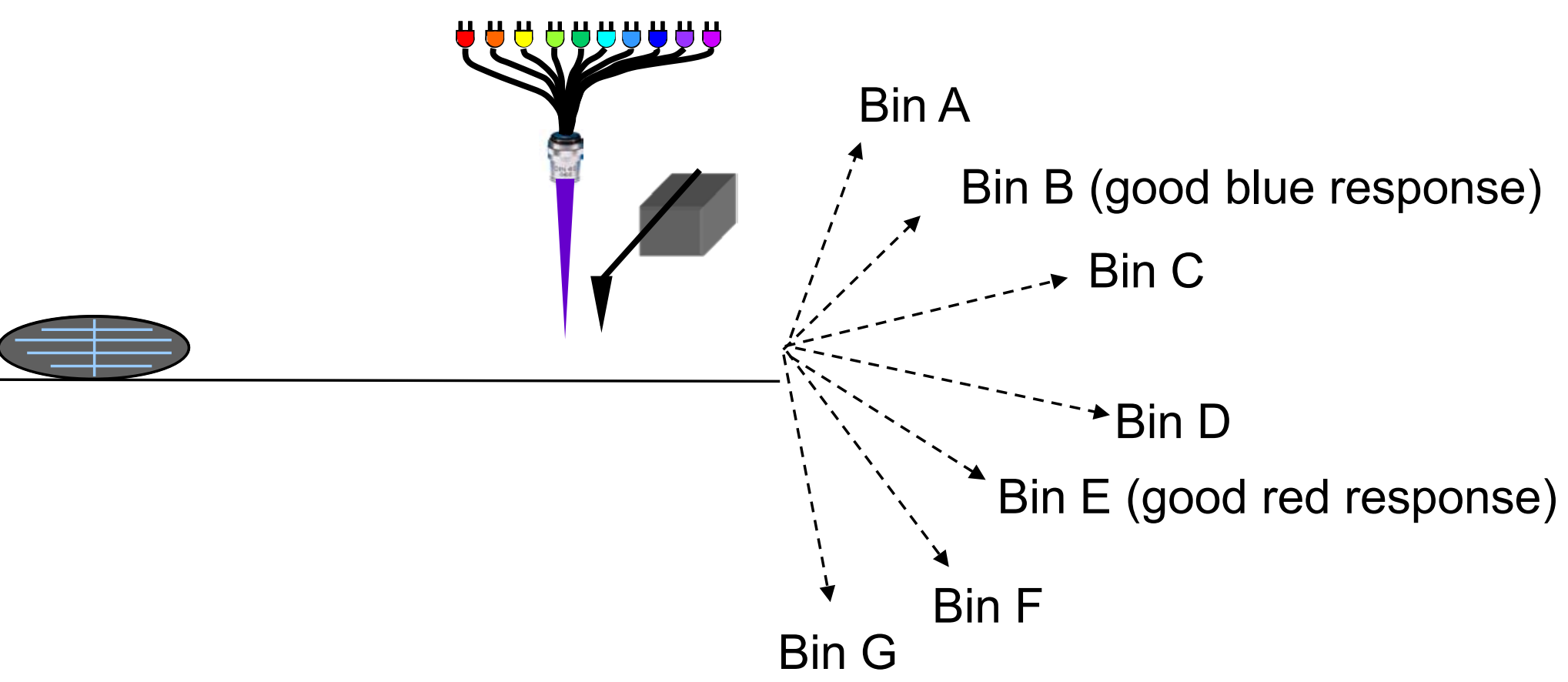




\section{In-line QE for solar cell manufacturing}

Benefits:

- In-line diagnostics for process control

- Device physics feedback

- Spectral-matching cell binning to maximize module KW-hr output

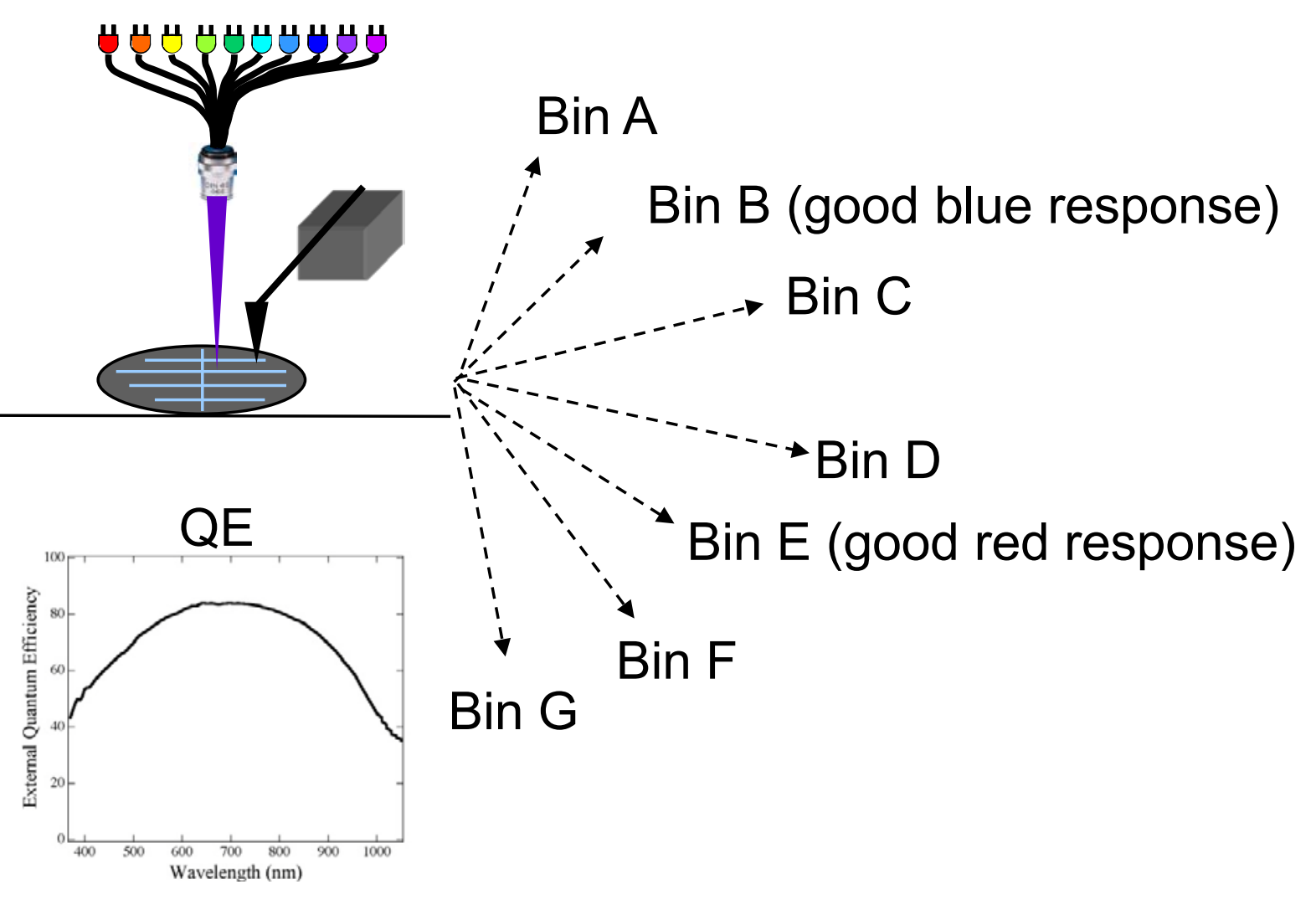




\section{In-line QE for solar cell manufacturing}

Benefits:

- In-line diagnostics for process control

- Device physics feedback

- Spectral-matching cell binning to maximize module KW-hr output

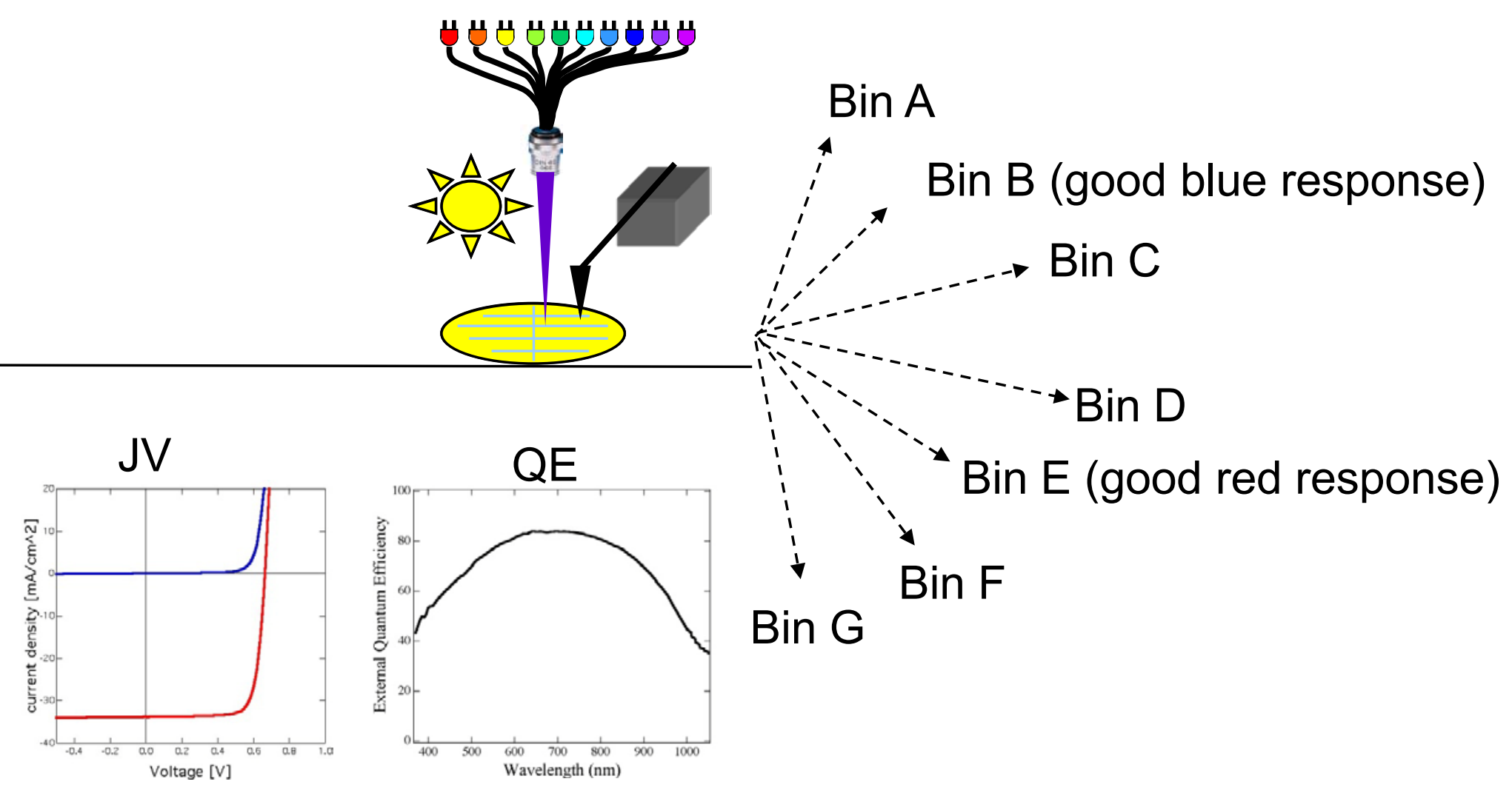




\section{In-line QE for solar cell manufacturing}

Benefits:

- In-line diagnostics for process control

- Device physics feedback

- Spectral-matching cell binning to maximize module KW-hr output

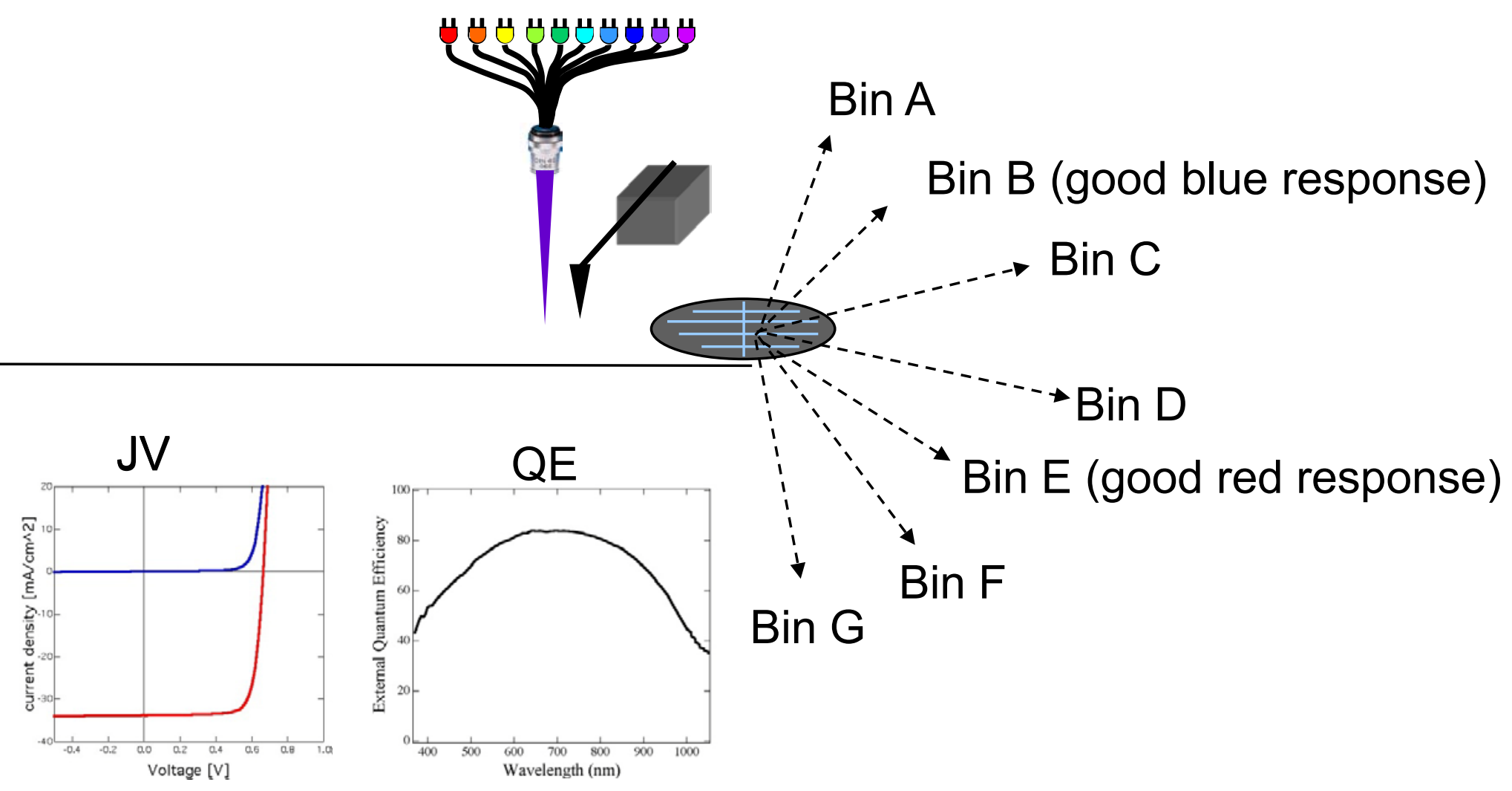




\section{In-line QE for solar cell manufacturing}

Benefits:

- In-line diagnostics for process control

- Device physics feedback

- Spectral-matching cell binning to maximize module KW-hr output

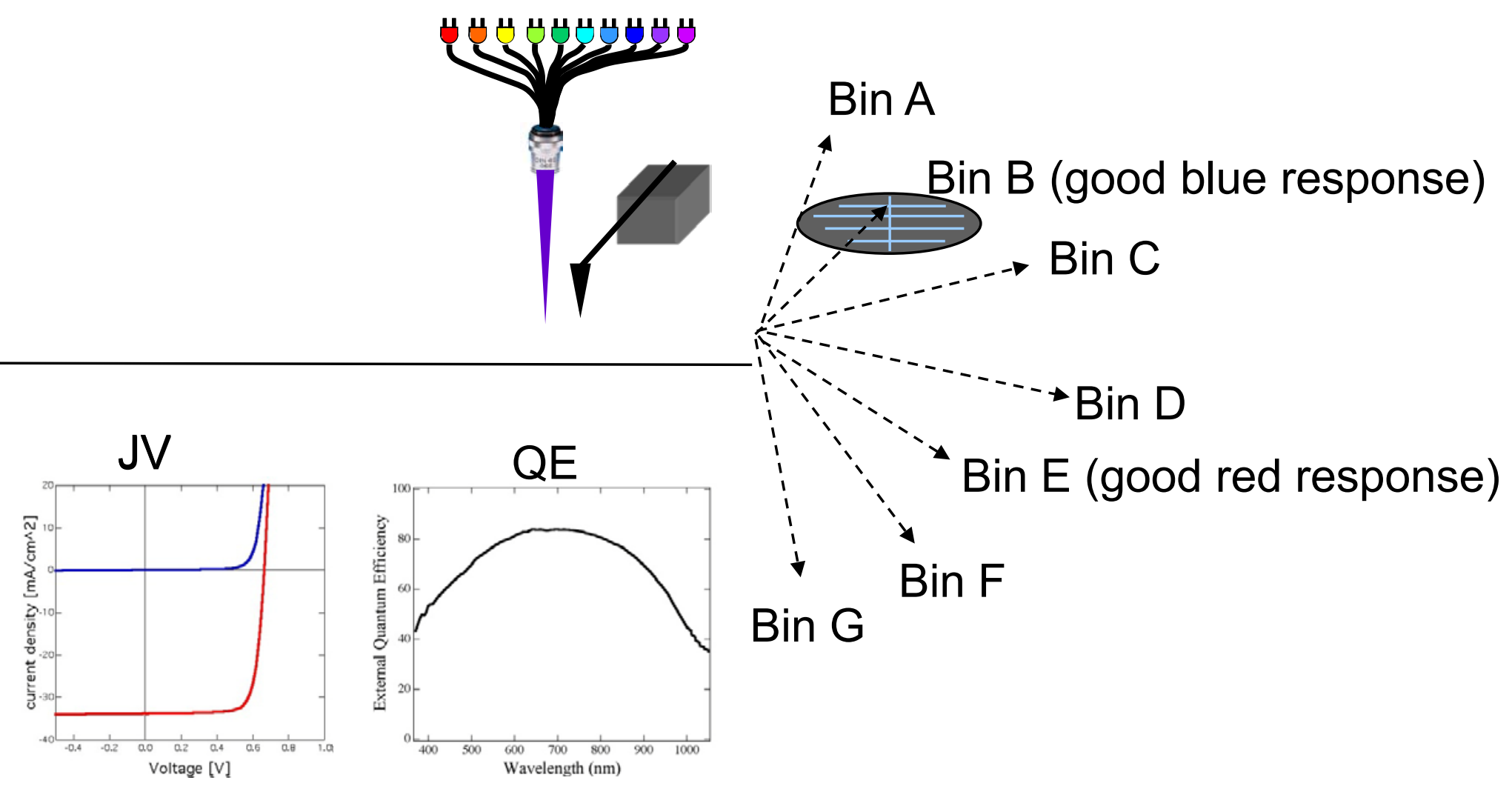




\section{In-line QE for solar cell manufacturing}

Benefits:

- In-line diagnostics for process control

- Device physics feedback

- Spectral-matching cell binning to maximize module KW-hr output

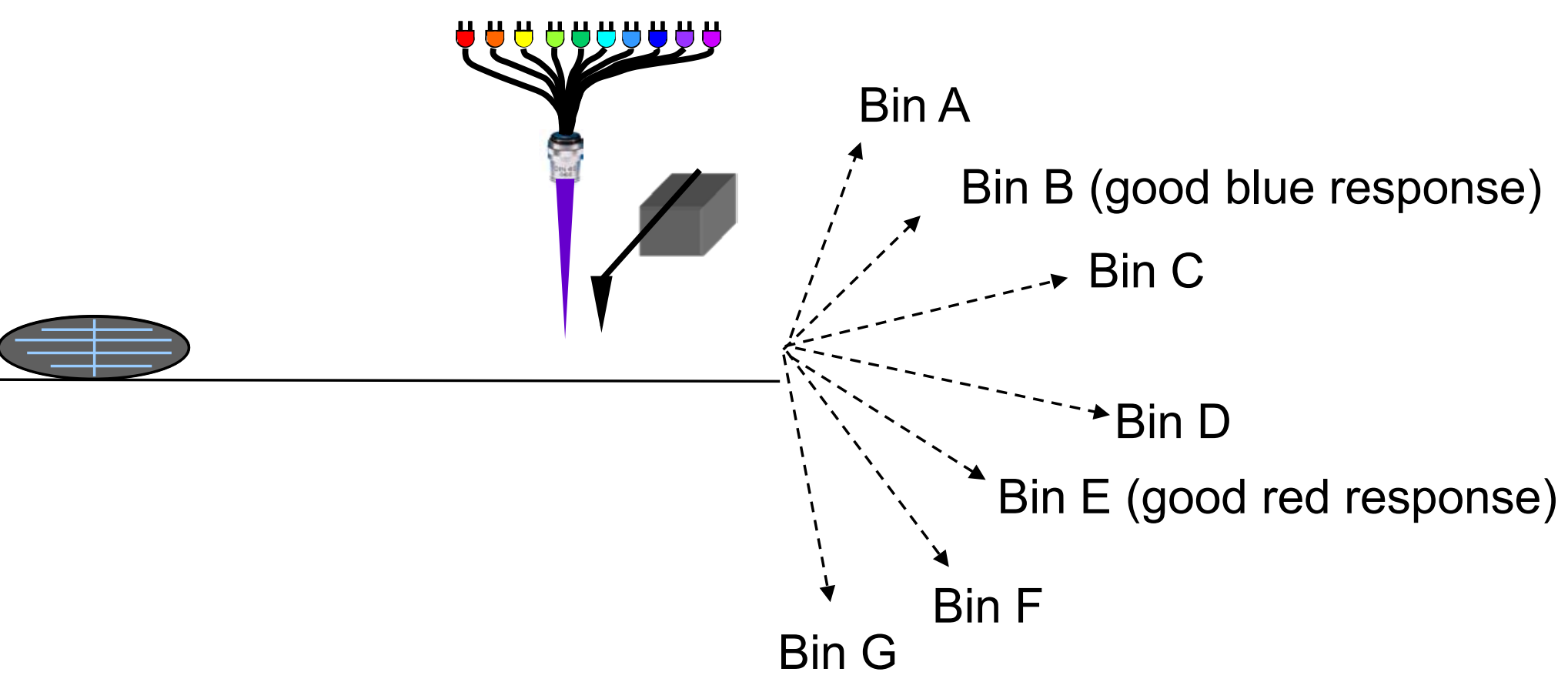




\section{In-line QE for solar cell manufacturing}

Benefits:

- In-line diagnostics for process control

- Device physics feedback

- Spectral-matching cell binning to maximize module KW-hr output

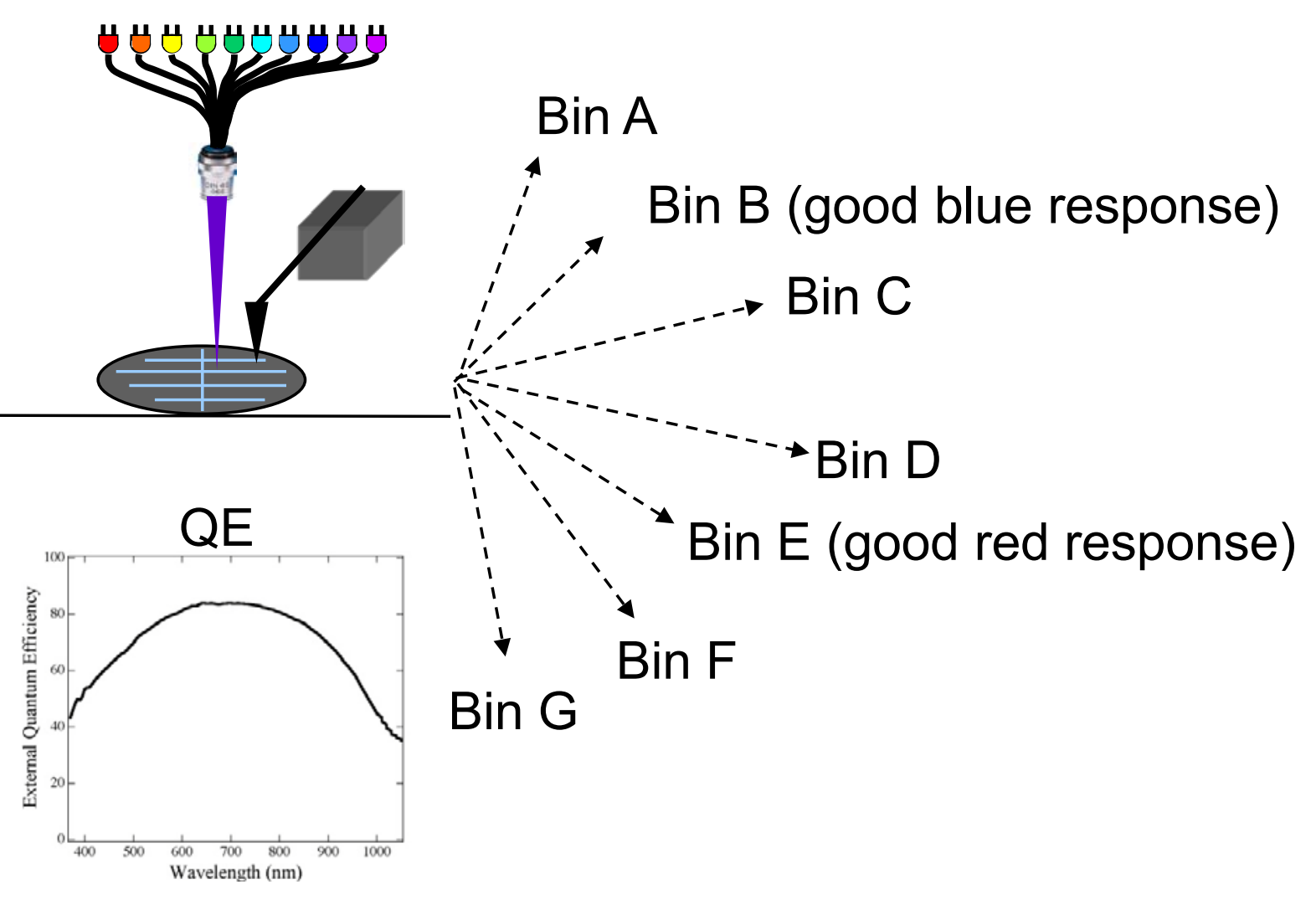




\section{In-line QE for solar cell manufacturing}

Benefits:

- In-line diagnostics for process control

- Device physics feedback

- Spectral-matching cell binning to maximize module KW-hr output

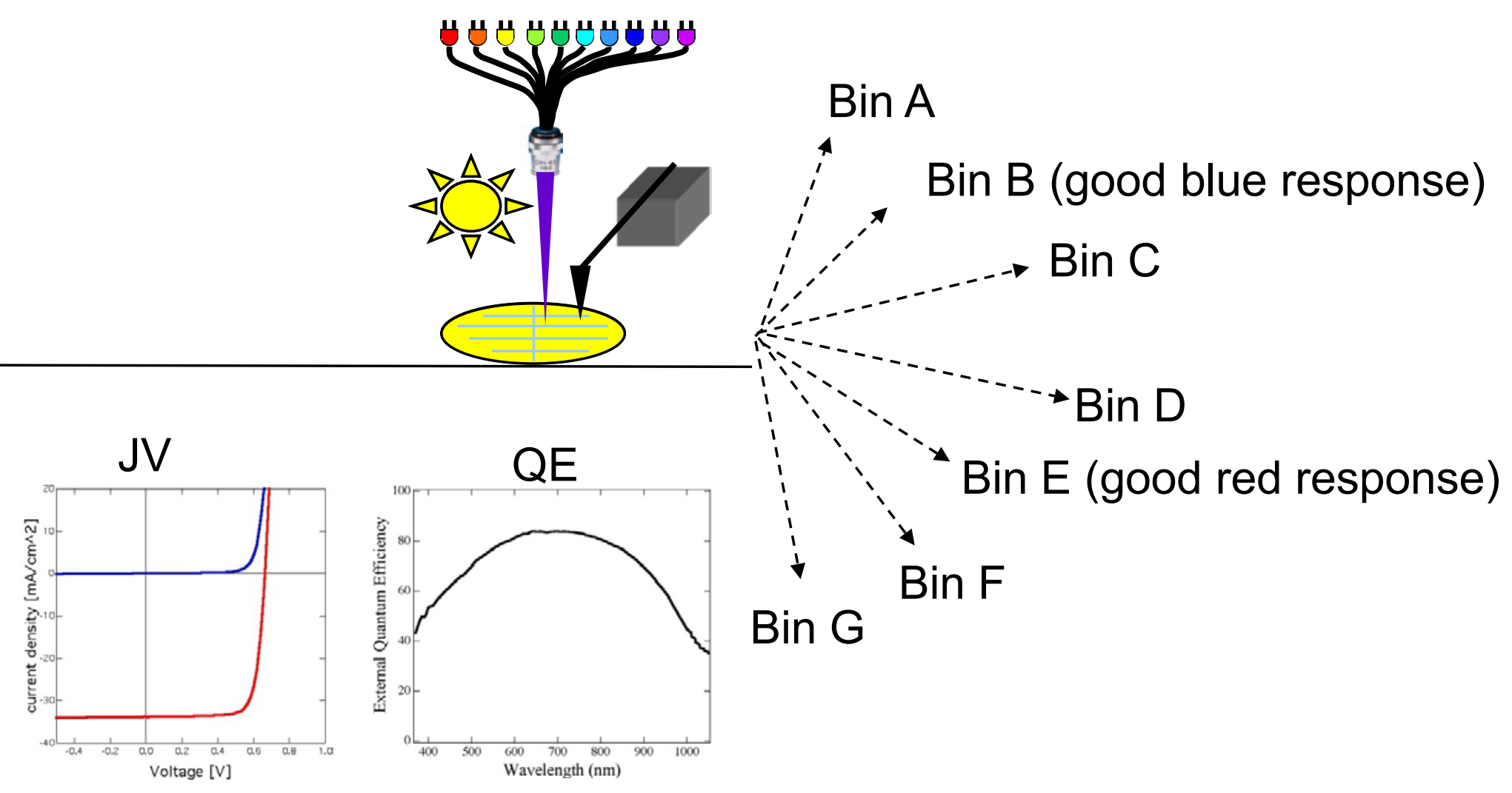




\section{In-line QE for solar cell manufacturing}

Benefits:

- In-line diagnostics for process control

- Device physics feedback

- Spectral-matching cell binning to maximize module KW-hr output

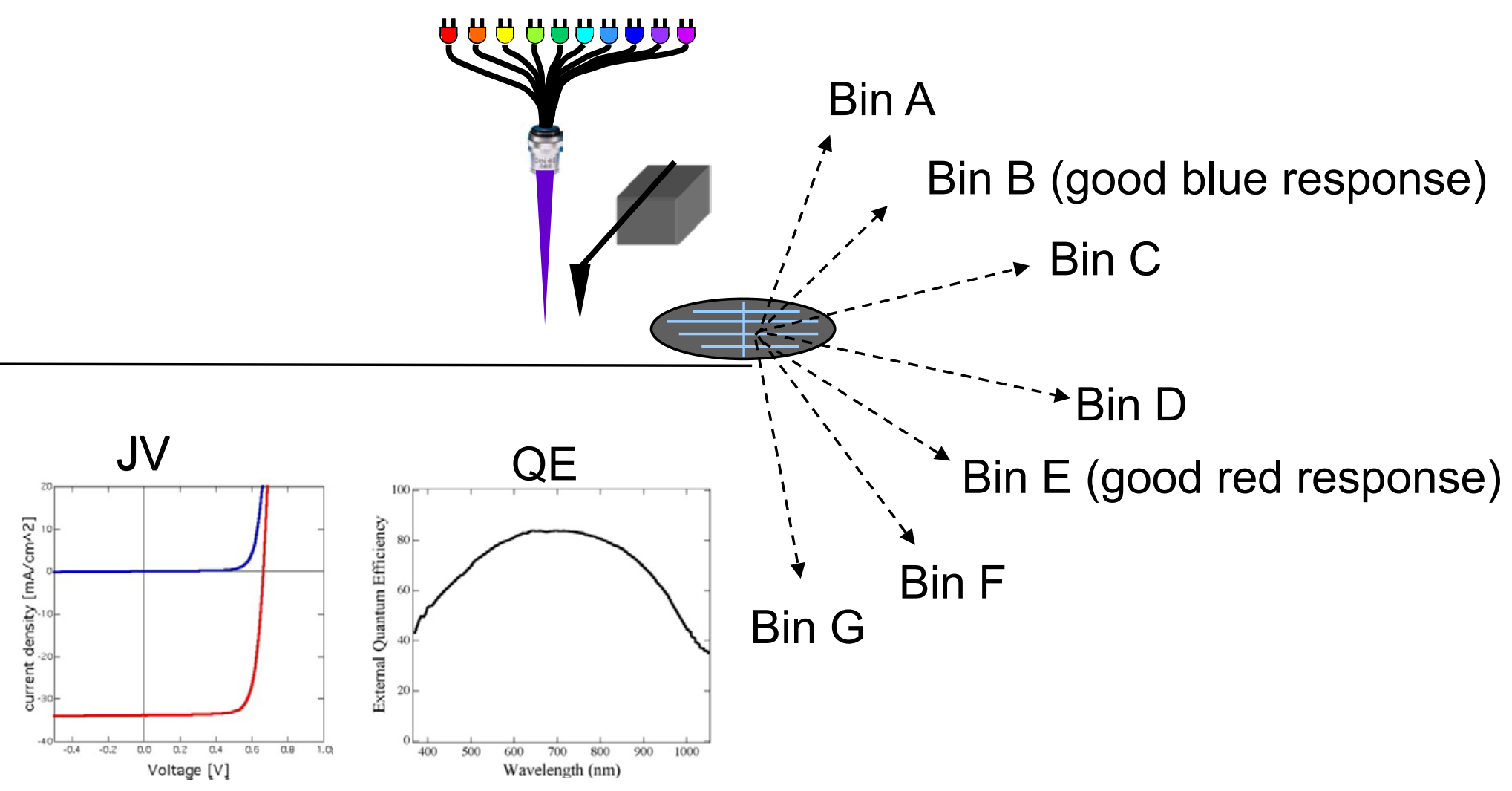




\section{In-line QE for solar cell manufacturing}

Benefits:

- In-line diagnostics for process control

- Device physics feedback

- Spectral-matching cell binning to maximize module KW-hr output

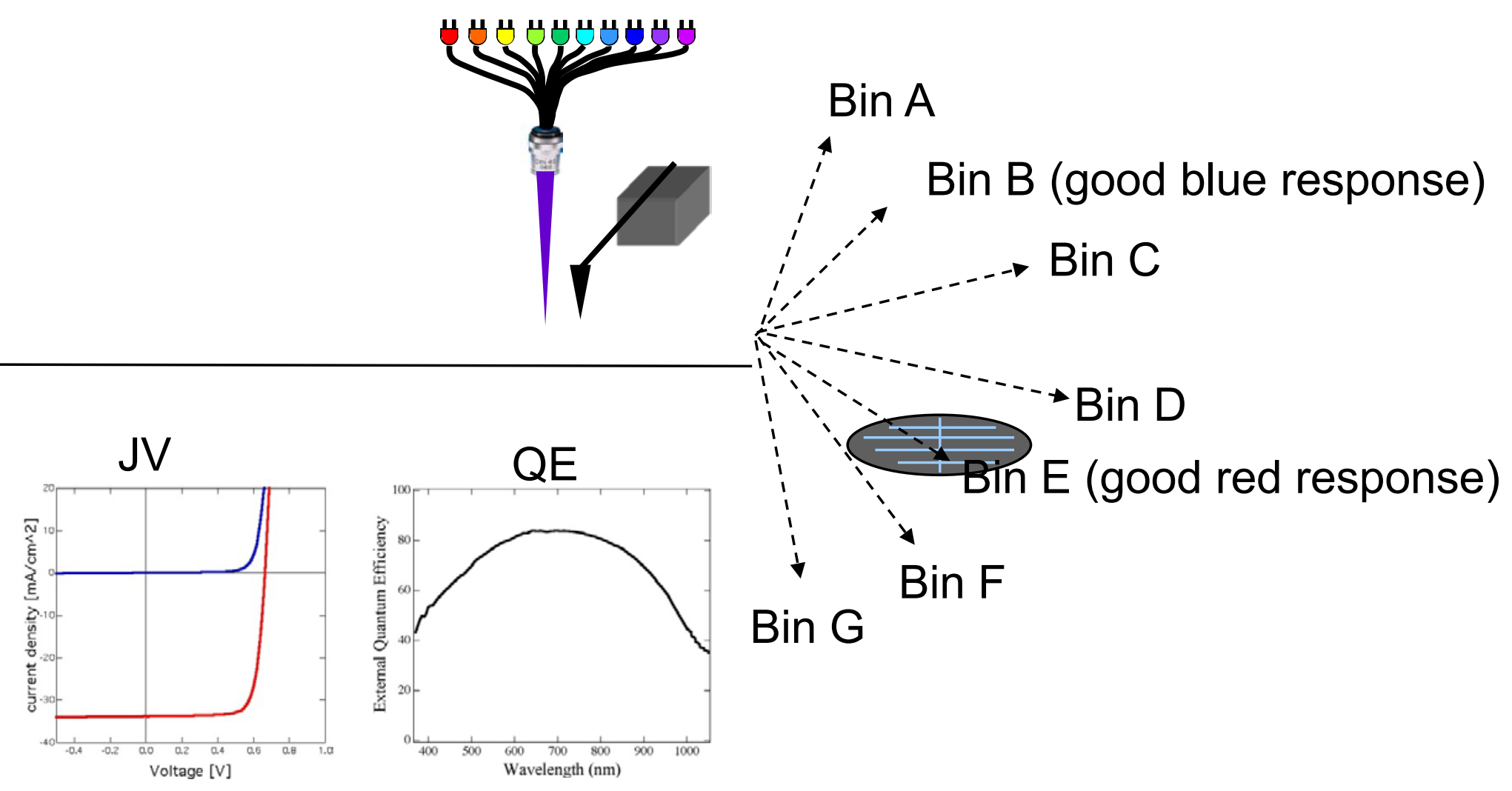




\section{Spatial spectral-response Mapping (cells, modules)}

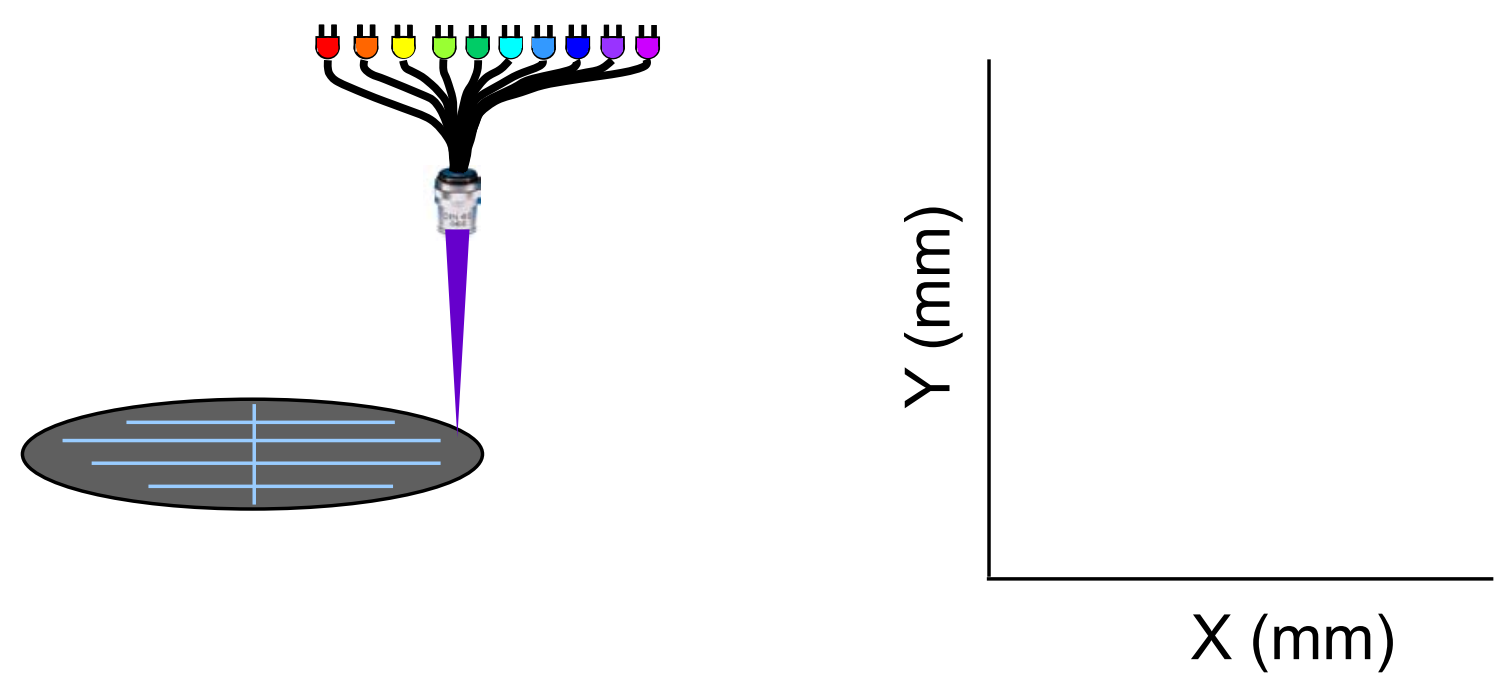




\section{Spatial spectral-response Mapping (cells, modules)}

Cell and module uniformity Defects

Process control

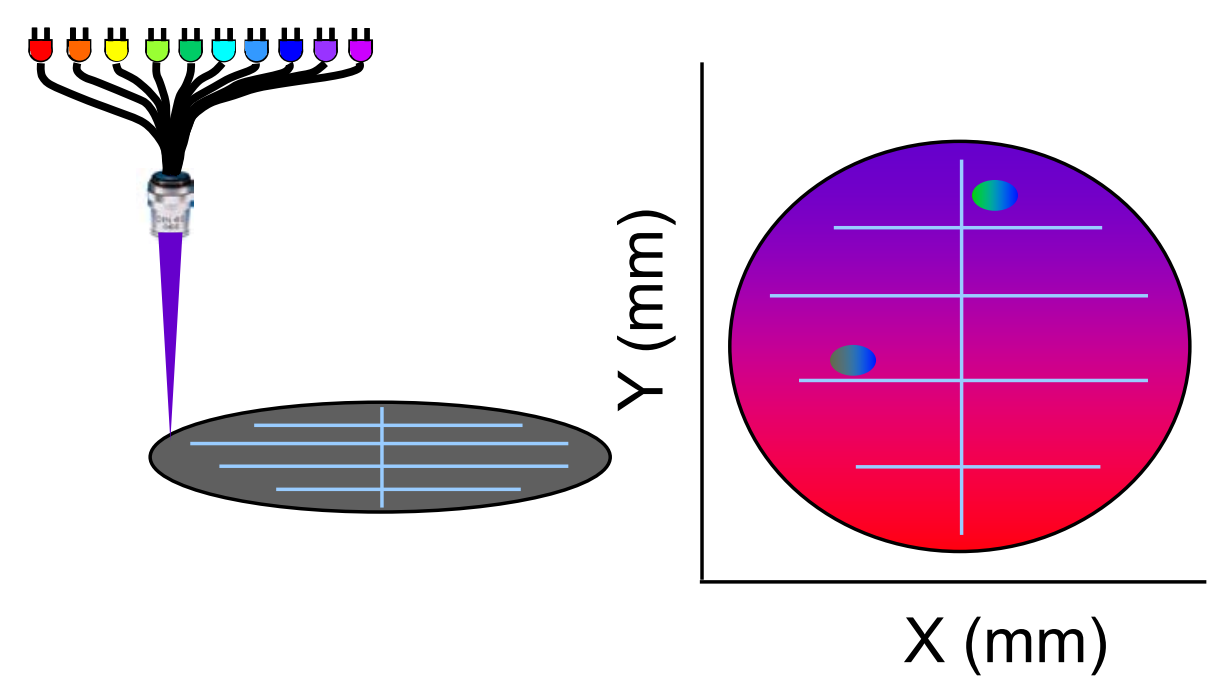


Electronic control of light spectrum

Multi-junction solar cell QE measurements

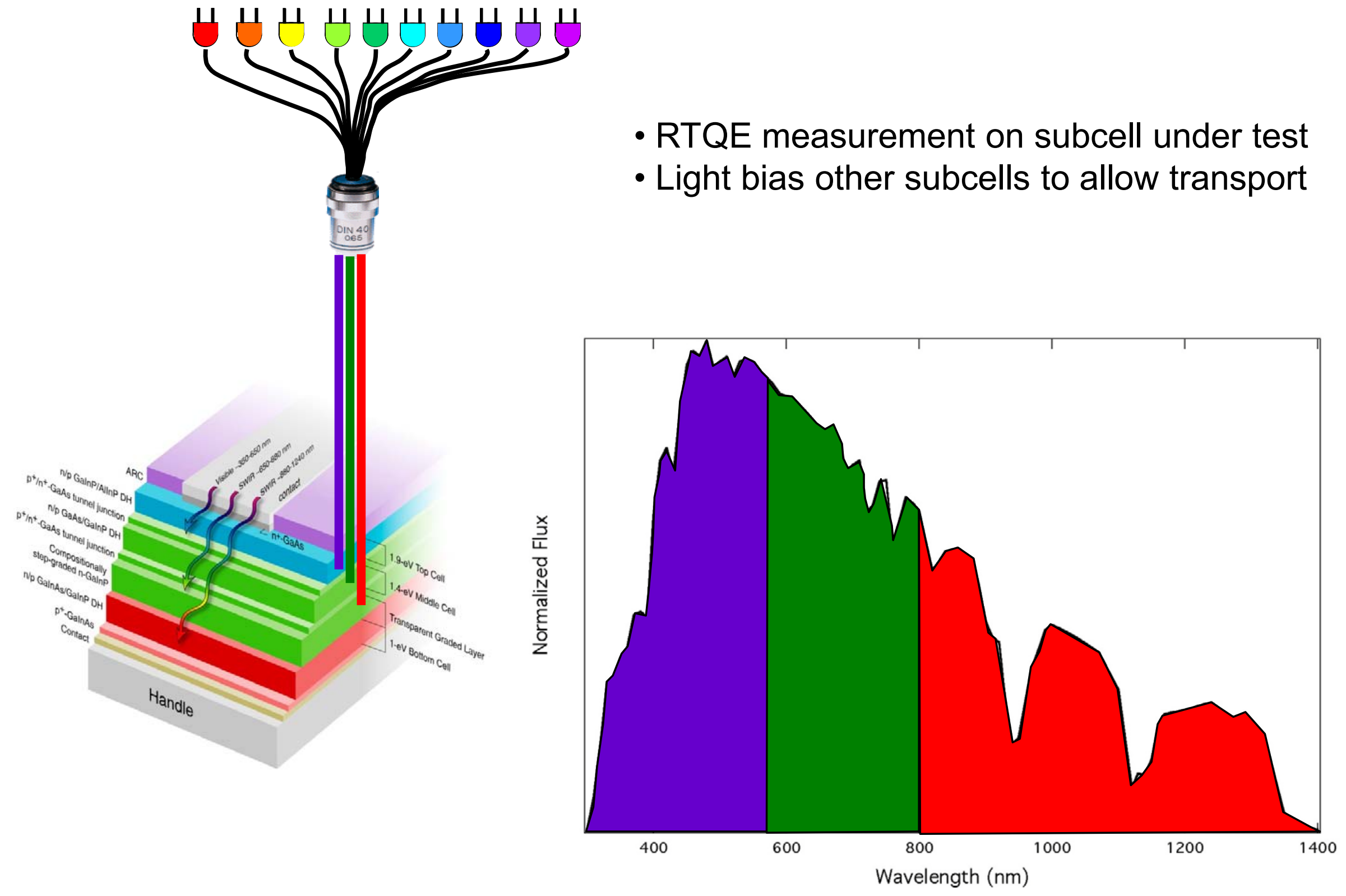




\section{NPEl National Renewable Energy Laboratory}

\section{Innovation for Our Energy Future}

\section{Real Time Quantum Efficiency Technique}

- Electronically controlled full-spectrum LED light source

- Parallel data processing

- Simple, robust, "inexpensive”, solid-state, FAST ( 1000 vs 1 QE Measurement during this talk)

\section{Expanded Applications}

- Industrial In-line diagnostics, spectral-matching cell sorting

- Spatial spectral response mapping

- Electronic filtering - tandem solar cell QE measurements

- Technique applicable to other spectroscopy techniques

Further information:

Technical: david_young@nrel.gov

Technology Licensing: david_christensen@nrel.gov 
Pure sine wave drive voltage:
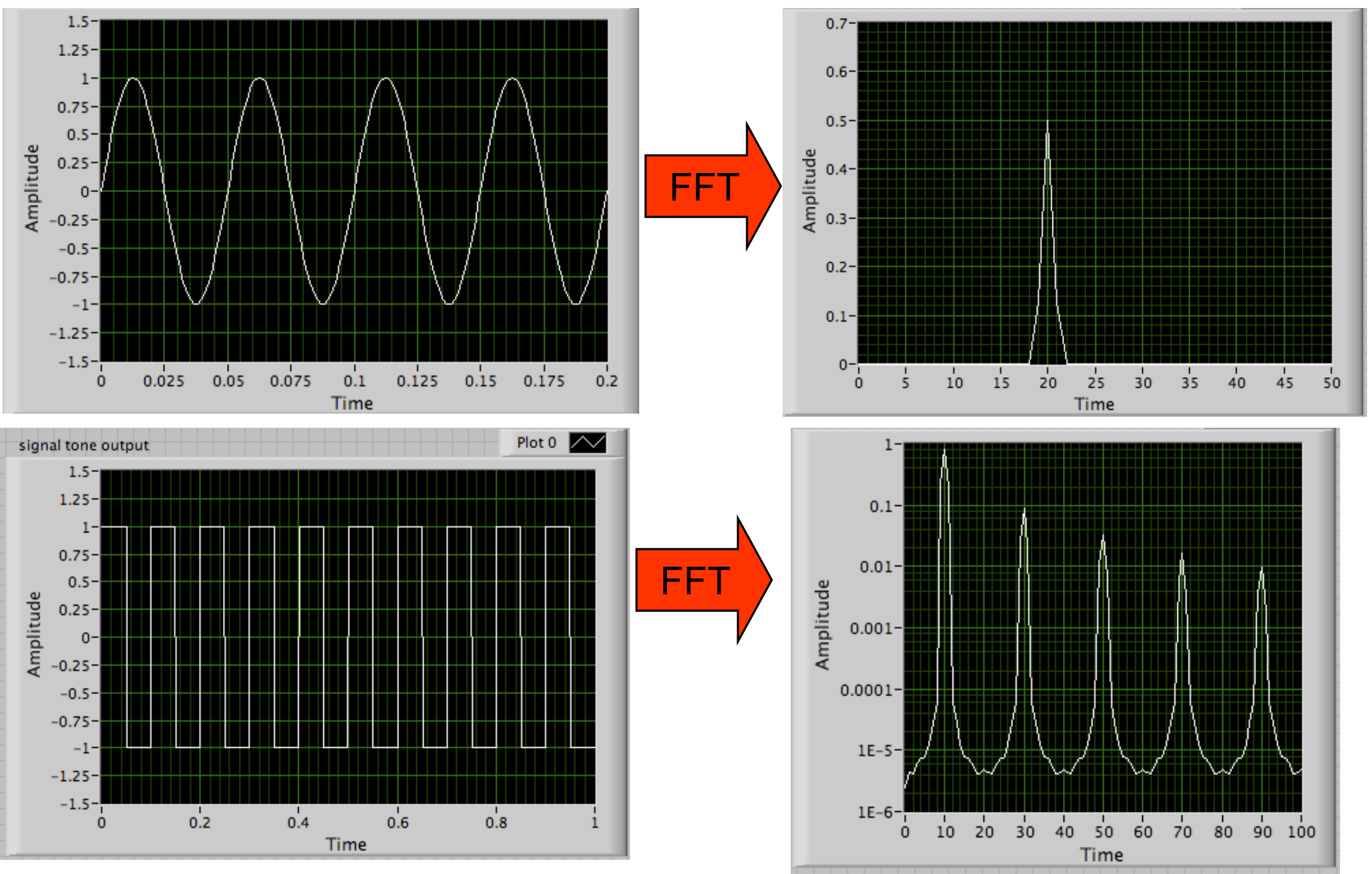

No multiple frequencies

fast data acquisition rate $<$ Drive frequencies $<1 /$ minority life time, acquisition/2 


\section{LED spectral width}
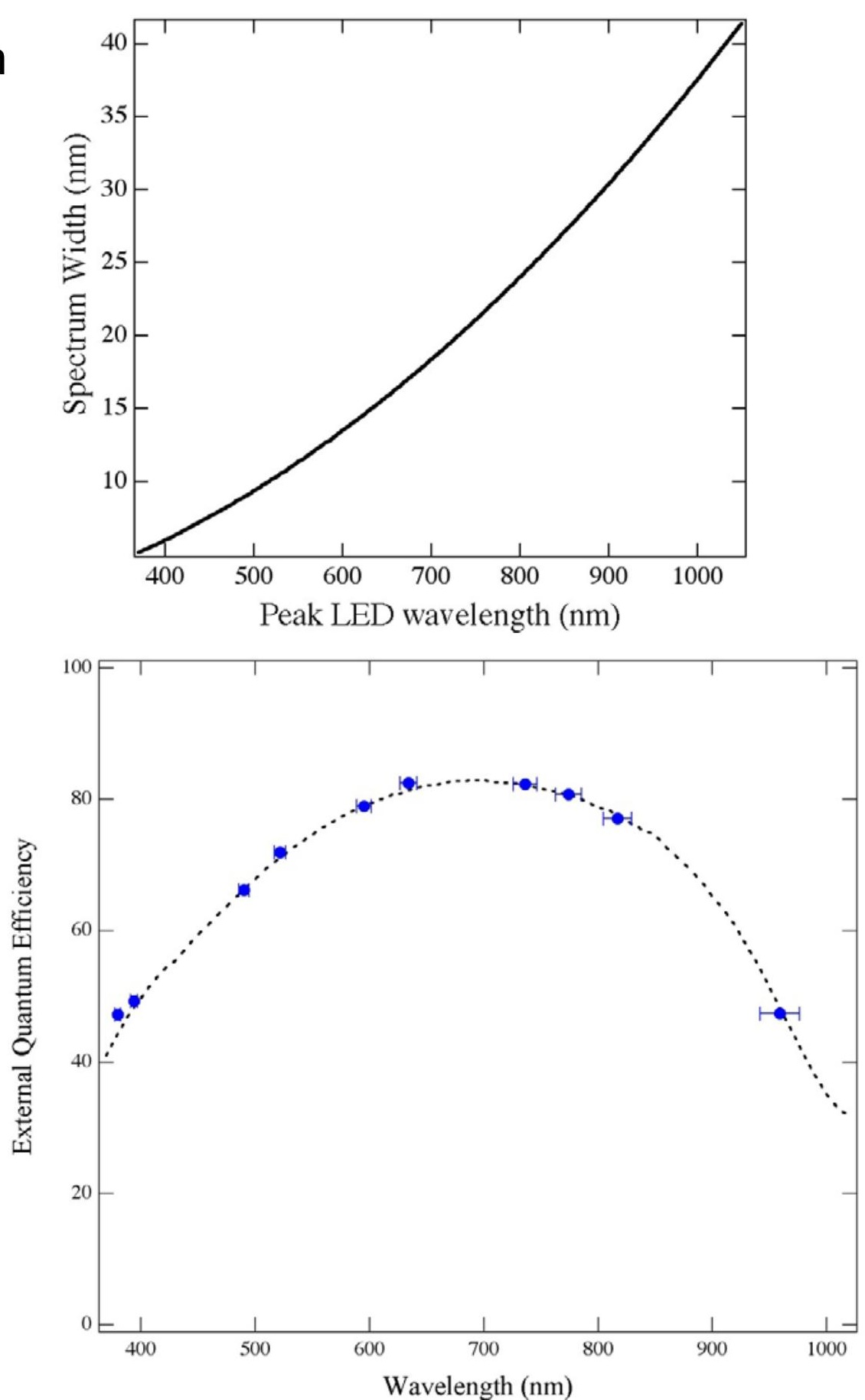